\title{
Insight into phytohormonal modulation of defense mechanisms to salt excess in a halophyte and a glycophyte from Asteraceae family
}

\author{
Alina Wiszniewska (D) - Aleksandra Koźmińska • Ewa \\ Hanus-Fajerska $\cdot$ Kinga Dziurka $\cdot$ Michal Dziurka
}

Received: 11 August 2020 / Accepted: 14 February 2021 / Published online: 1 March 2021

(C) The Author(s) 2021

\begin{abstract}
Aims The aim of this study was to compare the efficiency of three defense mechanisms (ionic balance, osmotic adjustment and counteracting oxidative stress) under low, moderate and high soil salinity in two related species of contrasting tolerance to salinity: the halophyte Aster tripolium and the glycophyte Aster alpinus, and to elucidate their phytohormone-mediated regulation.

Methods The phytohormonal profiling was performed to asses correlations between the pool of plant growth regulators and parameters depicting ionic homeostasis, osmotic adjustment and antioxidant system.

Results Defense mechanisms in both species were based on accumulation/activity of distinct compounds $\left(\mathrm{Na}^{+}\right.$and $\mathrm{K}^{+}$ions, antioxidants), but differences among species concerned particularly soluble carbohydrates and betaines. The halophyte accumulated mannitol, uronic acids and sucrose, while the glycophyte mostly glucose and proline-betaine. The halophyte responses also correlated with changes in the content of plant growth promoting PGRs, as well as jasmonates and
\end{abstract}

Responsible Editor: Wieland Fricke.

A. Wiszniewska $(\bowtie) \cdot$ A. Koźmińska $\cdot$ E. Hanus-Fajerska Department of Botany, Physiology and Plant Protection, Faculty of Biotechnology and Horticulture, University of Agriculture in Kraków, Al. 29 Listopada 54, 31-425 Kraków, Poland e-mail: a.wiszniewska@urk.edu.pl

K. Dziurka • M. Dziurka

The Franciszek Górski Institute of Plant Physiology, Polish Academy of Sciences, Niezapominajek 21, 30-239 Kraków, Poland benzoic acid. The glycophyte responses corresponded with changes in content of abscisic acid and ethylene precursor, as well as salicylic acid.

Conclusions We provided evidence that benzoic acid rather than salicylic acid is involved in salt tolerance in the halophyte and elevated SA content may enhance vulnerability to salt excess. An important element of tolerance trait is also JA-GA network that influences the intensity of defense responses. This study uncovers new aspects of internal phytohormonal regulation of plant reaction to soil salinity and enables further insight into extremophyte biology.

Keywords Antioxidants · Extremophyte - Ions · Osmolytes $\cdot$ Phytohormones $\cdot$ Relative taxa $\cdot$ Salt excess

$\begin{array}{ll}\text { Abbreviations } \\ \text { ABA } & \text { abscisic acid } \\ \text { ACC } & \text { 1-aminocyclopropane-1-carboxylic acid } \\ \text { Aux } & \text { auxins } \\ \text { BA } & \text { benzoic acid } \\ \text { Car } & \text { carotenoids } \\ \text { CAT } & \text { catalase (EC 1.11.1.6) } \\ \text { Chl } & \text { chlorophylls } \\ \text { Cyt } & \text { cytokinins } \\ \text { DW } & \text { dry weight } \\ \text { EC } & \text { electrical conductivity } \\ \text { FV } & \text { total flavonoids } \\ \text { FW } & \text { fresh weight } \\ \text { GA } & \text { gibberellins } \\ \text { GlyB } & \text { glycine betaine } \\ \text { GTI } & \text { growth tolerance index }\end{array}$




$\begin{array}{ll}\text { JA } & \text { jasmonates } \\ \text { MDA } & \text { malondialdehyde } \\ \text { OPDA } & \text { oxophytodienoic acid } \\ \text { PGR } & \text { plant growth regulators } \\ \text { POD } & \text { peroxidase } \\ \text { Pro } & \text { proline } \\ \text { ProB } & \text { proline betaine } \\ \text { SA } & \text { salicylic acid } \\ \text { SL } & \text { stem length } \\ \text { TBARS } & \text { thiobarbituric acid-reactive-substances } \\ \text { TPC } & \text { total phenolic content } \\ \text { TSC } & \text { total soluble carbohydrates } \\ \text { WC } & \text { water content }\end{array}$

\section{Introduction}

Excessive soil salinity is a destructive environmental factor that greatly reduces plant growth and productivity. General plant tolerance to suboptimal salinity mostly depends on the activation of a series of conserved mechanisms, among which three are particularly important: control of ion homeostasis, accumulation of osmolytes to maintain cellular osmotic balance, and activation of antioxidant system to counteract oxidative stress (Flowers and Colmer 2015; Rozema and Schat 2013). These basic mechanisms are not specific for stress-tolerant species only but are shared by all plants, and tolerance range in various species is attributed to their relative efficiency (Bartels and Dinakar 2013). Notwithstanding, defense responses and strategies to survive and sustain growth are highly complex and involve multiple pathways and molecules. Due to such complexity, it is often problematic to obtain a complete understanding of how a particular species responds to salinity (Li et al. 2010).

Recently, extended knowledge has been gathered considering physiological performance of halophytes in saline areas. These plants are extremely salt tolerant - they usually grow and survive in environments with salt concentrations as high as $5 \mathrm{~g} \cdot \mathrm{l}^{-1}$ (Joshi et al. 2015), being capable of surviving under a salt shock, for example due to tidal or rainfall events. Their structure and metabolism are notably adapted to suboptimal growth conditions of saline habitats (Ali and Yun 2017). Halophytes respond to salinity at cellular, tissue and whole plant level (Bercu et al. 2012; Kumari and Parida 2018). The main tolerance mechanism is based on ion accumulation and sequestration, to balance an internal osmotic status with external salinity (Flowers et al. 2010). This mechanism is supported by synthesis of versatile compatible solutes and significant boost in antioxidant activity. Insight into physiological control of halophyte responses to excessive salinity is the key to plant engineering for salt tolerance (Kumari et al. 2015; Rozema and Schat 2013). Particularly, the regulatory network conditioning salt tolerance in these extremophytes needs clarification (Maršálová et al. 2016). An important aspect are the interplays between endogenous phytohormones (PGRs) and their contribution to activation of a particular defense strategy (Benjamin et al. 2019; Ellouzi et al. 2014).

In stress physiology, PGRs are characterized as cellular signal molecules involved in the regulation of plant responses to unfavorable environmental conditions (Peleg and Blumwald 2011). Their signaling pathways are linked in a complex network, which provides plants with a regulatory potential to directly adapt to stress factors and avoid serious growth deterioration (Llanes et al. 2018). Even slight variations in endogenous PGR contents may change their physiological role and phytohormonal balance of an entire organism (Pieterse et al. 2009). In recent years, knowledge on PGR role in halophyte responses has grown significantly, e.g. thanks to the studies on hormone-biosynthetic pathways in saltsensitive glycophytic species (Gharbi et al. 2017; Gong et al. 2005; Prerostova et al. 2017). The wide range of salinity levels that halophytes can withstand is related to numerous biochemical responses involved in stress tolerance in these species. The most pronounced effects are various growth alterations, directly influenced by PGRs (Guo et al. 2020; Wiszniewska et al. 2019). Growth regulators control also the activation and efficiency of the general stress defense reactions (Julkowska and Testerink 2015; Sharma et al. 2019; Souza et al. 2017). Salinity leads to modifications in signal transduction of growth promoting as well as stress hormones, which may promote activation of specific protective mechanisms (Eyidogan et al. 2012). Although plant response to salt stress depends on many factors and their relative influence can vary between genotypes, still endogenous PGRs are considered critical in modulating physiological responses that eventually lead to adaptation to a harmful environment (Peleg and Blumwald 2011). Despite its uniformity and abundance in plants, 
pathways of phytohormonal control may differ substantially between salt-tolerant and saltsensitive genotypes (Dias et al. 2015; Prerostova et al. 2017).

Studies on related taxa of contrasting stress tolerance may facilitate understanding of the relative contribution of particular defense responses to plant ability to survive in stressful conditions (Al Hassan et al. 2017; Koźmińska et al. 2019). In this study, we have implemented such an approach to investigate the efficiency of salinity defense mechanisms and their correlations with fluctuation of endogenous PGRs in two species from Asteraceae family: a halophyte Aster tripolium (syn. Tripolium pannonicum subsp. tripolium (L.) Greuter), and a glycophyte Aster alpinus L. Sea aster (A. tripolium) is a perennial halophyte native to Eurasia and northern Africa, confined in its distribution to salt marshes, estuaries and occasionally to inland saline areas. This species grows up to $50 \mathrm{~cm}$ tall with fleshy lanceolate leaves and purple ray florets flowering from July to September. Sea aster is suitable for well-drained light (sandy), medium (loamy) and heavy (clay) soils, with wide range of $\mathrm{pH}$. It cannot grow in the shade (Shennan et al. 1987; Duarte et al. 2015). A. tripolium is already identified and used commercially as food source (Ventura et al. 2013). Alpine aster (A. alpinus) is native to the mountains of Europe, including the Alps and Pyrenees, and is the only North American species of 180 ones in this genus (Pennisi 2001), cultivated worldwide as an ornamental plant. This species belongs to the ecological group of xeromesophytes. It is an herbaceous perennial plant forming a clump to $30 \mathrm{~cm}$ in height, with narrow dark green leaves and daisy-like flowerheads to $5 \mathrm{~cm}$ in width. It grows in moderately fertile, medium moisture, well-drained soils in full sun, in narrow $\mathrm{pH}$ range (6-7.5). This species can survive medium heat and requires at least 90 frost-free days for proper growth and may struggle in the hot and humid climate (Korolyuk 1997; Szelag and Kobiv 2017; Filippova et al. 2019).

The species have been selected as a representatives of the complex genus, taking into account their distinct ecological features, mainly an ability to sustain growth in saline environment. A. tripolium is a halophyte capable of maintaining ionic homeostasis and counteract water loss. A. alpinus, as an alpine species, is also tolerant to limited water supply, however in its natural habitat it does not challenge osmotic disturbances caused by excessive uptake of soluble salts. For this reason it can be chosen as a referential species of glycophytic character.

The aim of this study was to compare the efficiency of three general defense mechanisms under low, moderate and high salinity in the halophyte and the glycophyte, and to elucidate their phytohormonemediated regulation. Our basic assumption was that the responses that are critical for tolerance should be more efficiently expressed in the halophyte than the glycophyte. This study also aimed at identification of particular PGRs related to species-dependent responses and the prevailing mode of defense mechanisms under distinct levels of salinity in salt-tolerant and saltsensitive Aster species.

\section{Materials and methods}

\section{Plant material}

Seeds of A. tripolium (Tripolium pannonicum subsp. tripolium (L.) Greuter) were obtained from the Natural Park 'La Albufera' (Province of Valencia, Spain), obtained from the seed socks of the 'Servicio DevesaAlbufera', and seeds of A. alpinus were purchased from a commercial supplier (POLAN Spółka z o.o.). Formal identification of plant material was conducted by Dr. Ewa Sitek, PhD, from Department of Botany, Physiology and Plant Protection, University of Agriculture in Kraków, Poland. Voucher specimens have been deposited in herbarium of the Department.

\section{Plant growth conditions and treatment}

Germination was carried out on standard Petri dishes at $25^{\circ} \mathrm{C}$ and $16 \mathrm{~h}$ photoperiod. After five weeks, seedlings were individually transplanted into $1 \mathrm{~L}$ pots $(\varnothing=$ $11 \mathrm{~cm})$, containing a moistened mixture of soil (50\%), perlite $(25 \%)$ and sand $(25 \%)$. During the entire course of plant growth the substrate was kept moist by adding $200 \mathrm{ml}$ Hoagland's nutrient solution to each pot twice a week.

Salt treatments started three weeks after the seedling transplantation. To this end ten individual seedlings (ten biological replicates) of uniform size per species and per treatment were selected and transferred to the pots; ten pots of each set were treated for four weeks. The plants were watered twice a week with freshly prepared aqueous $\mathrm{NaCl}$ solutions of increasing concentration (200, 
400 and $600 \mathrm{mM}$, representing and referred as to low, moderate and high salt stress, respectively), using $1.5 \mathrm{~L}$ per tray. The control, non-treated plants were watered with distilled water. All experiments were conducted in a controlled environment in a greenhouse, under the following conditions: long-day photoperiod $(16 \mathrm{~h}$ of light), temperature of $23{ }^{\circ} \mathrm{C}$ during the day and $17{ }^{\circ} \mathrm{C}$ at night.

\section{Soil analysis}

The electrical conductivity $\left(\mathrm{EC}_{1: 5}\right)$ of the substrate was checked at the end of the treatments (after 4 weeks) (Suppl. Table 1). Soil samples were taken from the five pots selected per treatment, air-dried and then passed through a $2 \mathrm{~mm}$ sieve. A soil: water (1:5) suspension was prepared in distilled water and stirred for $1 \mathrm{~h}$ at $600 \mathrm{rpm}$ and $21^{\circ} \mathrm{C}$. EC was measured with a Crison Conductivity meter 522 and expressed in $\mathrm{dSm}^{-1}$. The increase in $\mathrm{EC}_{1: 5}$ was basically linear, correlating with the concentration of the saline solutions used in the treatments. Substrate conditions varied under low salinity $\left(9.05 \mathrm{dSm}^{-1}\right.$ for A. alpinus and $7.11 \mathrm{dSm}^{-1}$ for A. tripolium, $P<0.05$ ), whereas under moderate and high salinity they were the same for both the halophyte and the glycophyte (Suppl. Table 1).

Plant growth parameters

After four weeks of salt treatment the following growth parameters were determined: stem length (SL), fresh (FW) and dry weight (DW), and percentage of water content in the leaves. SL and DW were expressed as percentages of the mean values determined for the corresponding controls, taken as $100 \%$. Control values of SL and DW were as follows:

$41 \mathrm{~cm}$ and $0.29 \mathrm{~g}$ (A. tripolium) and $21 \mathrm{~cm}$ and $0.22 \mathrm{~g}$ (A. alpinus), respectively.

To determine water content (WC), leaf samples were weighed (FW), dried at $65{ }^{\circ} \mathrm{C}$ until constant weight (72 h) and then reweighed (DW); water content of each sample was calculated as: $\mathrm{WC} \%=[(\mathrm{FW}-\mathrm{DW}) / \mathrm{FW}] \times$ 100.

Growth Tolerance Index (GTI) (\%) was calculated on the basis of DW of shoots using the formula:

GTI $=$ (mean DW of salinity-treated plants / mean DW of untreated plants $) \times 100$.
Ion content determination

Dry plant material was digested in a closed microwave system using $\mathrm{HNO}_{3}$, and the contents of $\mathrm{Na}$ and $\mathrm{K}$ were assessed using a PerkinElmer atomic emission spectrometer ICP-OES Optima 7300 DV and multielement ICP-IV Merck standard solution. The accuracy of the analytical methods was verified using GSS-8 certified reference material (GBW 07408; State Bureau of Meteorology, Beijing, China).

The content of chloride in plant samples was determined in aqueous extracts, prepared by incubating $0.1 \mathrm{~g}$ of dried, ground leaf and root material in $15 \mathrm{~mL}$ of water for $1 \mathrm{~h}$ at $95{ }^{\circ} \mathrm{C}$, and followed by filtration through a $0.80 \mu \mathrm{m}$ filter. Chloride ion content in DW was quantified using ion meter equipped with chloride ion selective electrode (9617BNWP Chloride Combination Electrode, Thermo Fisher Scientific).

Total soluble carbohydrates quantification

Total soluble carbohydrates (TSC) were measured according to Dubois et al. (1995). Dried material (DW) was ground and mixed with $80 \%$ methanol on a rocker shaker for 24-48 h. Sulfuric acid and 5\% phenol were added and mixed before absorbance readings were taken at $490 \mathrm{~nm}$. TSC contents were expressed as 'mg equivalent of glucose' per gram of DW.

Chlorophyll and carotenoid content

Five mg of lyophilized and homogenized sample were extracted in $1.5 \mathrm{~mL}$ of $95 \%$ ethanol for $15 \mathrm{~min}$ and centrifuged at $2000 \mathrm{~g}$ (Universal 32R, Hettich, Germany) for $10 \mathrm{~min}$. The clear supernatant $(100 \mu \mathrm{L})$ was transferred to a 96-well microplate and absorbance was measured at 470, 648 and $664 \mathrm{~nm}$ spectrophotometrically with a microplate reader (Synergy II; Bio-Tek, USA). The concentrations of total chlorophyll $\mathrm{a}+\mathrm{b}$ (Chl) and carotenoids (Car) were calculated according to the equations given by Lichtenthaler and Buschmann (2001), taking into account that the path length of microwells was filled to a quarter of their depth. Concentrations reported are averages of three biological replications, each consisting of two analytical replications, and the values were later converted to $\mathrm{mg} \cdot \mathrm{g}^{-1}$ DW. 
Lipid peroxidation

Malondialdehyde (MDA) content was determined in $80 \%(\mathrm{v} / \mathrm{v})$ methanol extract of $100 \mathrm{mg}$ of fresh plant material (FW). MDA content was determined by the thiobarbituric acid-reactive-substances (TBARS) assay, modified to correct for the presence of interfering compounds, as described by Hodges et al. (1999).

\section{Activity of antioxidant enzymes}

The activity of enzymes was determined in the fresh leaves (FW) with the use of a Double Beam spectrophotometer U-2900 (Hitachi). Catalase (CAT) activity was measured according to the method described by Aebi (1984) and peroxidase (POD) activity by Lück (1962). $100 \mathrm{mg}$ of fresh plant material (FW) was homogenized in $5 \mathrm{~mL}$ ice-cold phosphate buffers with $\mathrm{pH} 7.0$ for CAT and $\mathrm{pH} 6.2$ for POD. The samples were centrifuged at $4{ }^{\circ} \mathrm{C}$ for $15 \mathrm{~min}$ at $4800 \mathrm{~g}$. For CAT activity analysis, $0.2 \mathrm{~mL}$ of the extract and $1.8 \mathrm{~mL}$ of the buffer were mixed with $1 \mathrm{~mL}$ of $\mathrm{H}_{2} \mathrm{O}_{2}$ solution in phosphate buffer. The absorbance of $\mathrm{H}_{2} \mathrm{O}_{2}$ decomposed by CAT was measured at $240 \mathrm{~nm}$ for $4 \mathrm{~min}$ at 1-min intervals. The unit of CAT activity was the amount of the enzyme that decomposed $1 \mu \mathrm{mol} \mathrm{H}_{2} \mathrm{O}_{2}$ in $1 \mathrm{~min}$. For analysis of POD activity, p-phenyldiamine was used as the enzyme substrate, which is oxidized by POD to phenazine. One $\mathrm{mL}$ of the extract, $1 \mathrm{~mL}$ of phosphate buffer, $0.1 \mathrm{~mL}$ of $1 \%$ solution of $\mathrm{p}$-phenyldiamine were mixed with $0.1 \mathrm{~mL}$ of $0.1 \% \mathrm{H}_{2} \mathrm{O}_{2}$. The absorbance of colored reaction product was measured at $485 \mathrm{~nm}$. One unit of POD activity corresponds to an absorbance increase of 0.1 .

\section{Non-enzymatic antioxidants}

Total flavonoids (FV) were measured in methanol extracts $(0.1 \mathrm{~g}$ of dried material in $3 \mathrm{~mL}$ of $80 \%$ methanol) and determined following the method described by Zhishen et al. (1999); the absorbance was measured at $510 \mathrm{~nm}$, and the amount of flavonoids was expressed in equivalents of catechin (mg C eq. $\cdot \mathrm{g}^{-1} \mathrm{DW}$ ), used as standard.

Total phenolic compounds (TPC) were determined according to the modified method of Singleton et al. (1999) using lyophilized plant material. A clear supernatant $(50 \mu \mathrm{L})$ was diluted with $0.5 \mathrm{~mL}$ of deionized water and $0.2 \mathrm{~mL}$ of Folin-Ciocalteu reagent, and after
10 min $0.7 \mathrm{~mL}$ saturated $\mathrm{Na}_{2} \mathrm{CO}_{3}$ was added. The samples were incubated for $2 \mathrm{~h}$, mixed and transferred to 96well plates. Absorbance was measured at $765 \mathrm{~nm}$ on a micro-plate reader (Synergy 2, Bio-Tek Winooski, VT, USA). The level of total phenolics was expressed in equivalents of chlorogenic acid (CA) (mg CA eq $\cdot \mathrm{g}^{-1}$ DW) used as standard.

Metabolite profiling (determination of phytohormones, carbohydrates and stress-related amino acids)

Analyzes of soluble carbohydrates and endogenous phytohormones were conducted using HPLC (LC-MS) and UHPLC according to the same procedures as described earlier (Wiszniewska et al. 2019). The content of those metabolites in DW was measured in lyophilized leaf samples of the stressed plants and the corresponding controls. Details on equipment characteristics, compound extraction, separation and used standards are given in Supplementary Material 3. The measurements for each treatment were taken in 6 replicates. The carbohydrate profile included the following compounds: sugar alcohols: inositol, glycerol, arabitol, mannitol; oligosaccharides (including fructans): kestose, kestopentatose, nystose, rafinose, stachiose, maltotriose; mono- and disaccharides: glucose, fructose, sucrose, maltose; uronic acids: glucuronic acid, galacturonic acid. In the phytohormonal profiling the following PGRs were monitored: abscisic acid (ABA) (active: $( \pm$ )trans, trans-ABA, $( \pm)$-cis, trans-ABA, inactive: $( \pm)$ cis,trans-ABA glucosyl ester); 1-aminocyclopropane1-carboxylic acid (ACC), auxins (active: indole-3acetic acid, indole-3-butyric acid, 4-chloroindole-3acetic acid, 5- chloroindole-3-acetic acid; conjugated: indole-3-acetyl-L-aspartic acid, indole-3-acetyl-Lglutamic acid, indole-3-carboxylic acid, indole-3-acetic acid methyl ester; oxidized: 2-oxo-3-indolineacetic acid); cytokinins (active: N6-isopentenyladenine, transzeatin, dihydrozeatin, cis-zeatin, meta-topolin, kinetin; trans-zeatin riboside, dihydrozeatin riboside, cis-zeatin riboside, kinetin riboside, $\mathrm{m}$-topolin riboside, N6isopentenyladenosine; deactivated: trans-zeatin-7-glucoside, trans-zeatin-O-glucoside); gibberellins (active: gibberellic acid, gibberellin A1, gibberellin A4; intermediate: gibberellins A5, A6, A7, A9; deactivated: gibberellin A8), jasmonic acid forms (active: $( \pm$ )-jasmonic acid, $( \pm$ )-jasmonic acid methyl ester; precursor: 12-oxophytodienoic acid) and salicylic and benzoic acids. Quantitations were based on calibration curves obtained 
with pure standards of all compounds. Glycine betaine (GlyB), stachydrine (proline betaine, ProB) and free proline were estimated in the same samples simultaneously with ACC, and D-ACC was used as internal standard.

The detected carbohydrates and phytohormones were classified into groups and presented accordingly as described before (Wiszniewska et al. 2019).

Statistical analysis

The experiment was repeated three times. Ten pots with one plant per experimental treatment constituted a replicate. Data were statistically analyzed using STATISTICA 13.0 software (StatSoft, Tulsa, OK, USA): one way ANOVA to asses differences between the species-specific responses to progressive salt concentrations, and to compare reaction of each species to particular salinity level. Correlation matrix was applied to determine the level of correlation between the changes in PGR content and changes in individual biochemical parameters.

\section{Results}

Profile of plant growth regulators in plants subjected to salinity

Auxins

Under salinity total level of auxins (Aux) increased substantially in A. alpinus. However, only 3-8\% of this pool accounted for active compounds, depending on the salinity level (Table 1, Suppl. Table 2). Increments in the pool of inactive Aux (both conjugated and oxidized) begun yet under low salinity. Contrary to that, A. tripolium was capable of maintaining constant content of active and inactive (oxidized and conjugated) Aux under low and moderate salinity in comparison to control conditions. Aux inactivation level increased only under high salinity. In both species, the proportions between the pool of active and inactive Aux were similar (Table 1).

Cytokinins

Concentrations of cytokinins (Cyt) were not affected by any of the applied salinity level in either species, as compared to untreated plants (Table 1). The prevailing compound was intermediate Cyt in a form of ribosides (four times more abundant than inactive Cyt-glucosides and twice as abundant as the active forms). The concentrations amounted to $0.8-0.9 \mathrm{nmol} \mathrm{g}^{-1} \mathrm{DW}$ in A. tripolium and $0.9-1.0 \mathrm{nmol} \mathrm{g}^{-1} \mathrm{DW}$ in A. alpinus $(P>0.05)$.

\section{Gibberellins}

In both studied species, accumulation of active and inactive gibberellins (GA) in response to salinity was not influenced by increasing external $\mathrm{NaCl}$ concentrations (Table 1). The pool of active GA differed among the species under moderate salinity, whereas the content of inactive GA was higher in halophyte under high salinity conditions. Salinity affected accumulation of GA intermediates, the contents of which increased in A. tripolium under moderate and high salinity (Table 1). In A. alpinus, the pool of GA intermediates increased under low and moderate salinity $(P>0.05)$ while in plants exposed to high salt stress it was the same as in the control. Regardless salinity level, the content of GA intermediates was higher in A. alpinus than in A. tripolium (Table 1).

Stress hormones: abscisic acid, jasmonates and ethylene precursor

Control A. tripolium plants had high initial ABA concentration, which declined under low and moderate salinity and increased again under high salinity (Table 2, Suppl. Table 1). An opposite trend was observed in A. alpinus, where initial concentration of active ABA forms was low (11 $\left.\mathrm{nmol} \mathrm{g}^{-1} \mathrm{DW}\right)$, and increased under low and moderate salinity (Table 2). Under high salinity ABA content was the same as in the control. In this species, there was a decrement in inactive ABA-glucoside content that was not observed in A. tripolium.

Initial concentration of active JA did not differ between A. tripolium and A. alpinus, and species reactions to salinity were similar (Table 2 ). The content of active JA declined, while jasmonic acid precursor oxophytodienoic acid (OPDA) increased in salt-treated plants, regardless of salinity intensity.

In control conditions the content of ethylene precursor (1-aminocyclopropane-1-carboxylic acid, ACC) was comparable in A. tripolium and A. alpinus. It 
Table 1 The content of endogenous growth-promoting phytohormones in A. tripolium and A. alpinus subjected to salinity

\begin{tabular}{|c|c|c|c|c|c|c|c|c|c|}
\hline \multirow{3}{*}{ Salinity level $^{\mathrm{a}}$} & \multicolumn{9}{|c|}{ Endogenous phytohormones $\left(\mathrm{nmol}^{-\mathrm{g}^{-1}} \mathrm{DW}\right)$} \\
\hline & \multicolumn{3}{|l|}{ Auxins } & \multicolumn{3}{|l|}{ Cytokinins } & \multicolumn{3}{|l|}{ Gibberellins } \\
\hline & $A_{c t v^{\mathrm{b}}}$ & Deact $^{\mathrm{c}}$ & & Actv & Inter $^{\mathrm{f}}$ & Deact & Actv & Inter & Deact \\
\hline & & $O x o^{\mathrm{d}}$ & Conj $^{\mathrm{e}}$ & & & & & & \\
\hline \multicolumn{10}{|l|}{ A. tripolium } \\
\hline none & $1.4 \pm 0.1 \mathrm{aA}$ & $1.3 \pm 0.2 \mathrm{bA}$ & $12.5 \pm 4.4 \mathrm{aA}$ & $0.4 \pm 0.0 \mathrm{aB}$ & $0.9 \pm 0.1 \mathrm{aA}$ & $0.04 \pm 0.0 \mathrm{aA}$ & $2.0 \pm 0.9 \mathrm{aA}$ & $7.3 \pm 0.7 \mathrm{aA}$ & $1.6 \pm 0.1 \mathrm{aA}$ \\
\hline low & $1.1 \pm 0.2 \mathrm{aA}$ & $1.2 \pm 0.1 \mathrm{bA}$ & $10.8 \pm 2.2 \mathrm{aA}$ & $0.4 \pm 0.0 \mathrm{aA}$ & $0.8 \pm 0.0 \mathrm{aA}$ & $0.1 \pm 0.0 \mathrm{aA}$ & $3.2 \pm 1.1 \mathrm{aA}$ & $11.9 \pm 3.1 \mathrm{aA}$ & $2.6 \pm 0.3 \mathrm{aA}$ \\
\hline moderate & $1.7 \pm 0.1 \mathrm{aA}$ & $0.3 \pm 0.0 \mathrm{aA}$ & $11.9 \pm 2.5 \mathrm{aA}$ & $0.3 \pm 0.0 \mathrm{aA}$ & $0.9 \pm 0.0 \mathrm{aA}$ & $0.1 \pm 0.0 \mathrm{aA}$ & $0.7 \pm 0.2 \mathrm{aA}$ & $18.2 \pm 1.1 \mathrm{bA}$ & $2.3 \pm 2.0 \mathrm{aA}$ \\
\hline high & $3.2 \pm 1.8 \mathrm{bA}$ & $2.7 \pm 1.9 \mathrm{cA}$ & $59.1 \pm 0.6 \mathrm{bA}$ & $0.5 \pm 0.3 \mathrm{aB}$ & $0.9 \pm 0.3 \mathrm{aA}$ & $0.04 \pm 0.0 \mathrm{aA}$ & $1.9 \pm 1.6 \mathrm{aA}$ & $23.1 \pm 5.4 \mathrm{cA}$ & $3.7 \pm 0.9 \mathrm{aB}$ \\
\hline \multicolumn{10}{|l|}{ A. alpinus } \\
\hline none & $3.0 \pm 0.1 \mathrm{aB}$ & $0.7 \pm 0.1 \mathrm{aA}$ & $5.5 \pm 1.8 \mathrm{aA}$ & $0.2 \pm 0.2 \mathrm{aA}$ & $1.0 \pm 0.0 \mathrm{aA}$ & $0.1 \pm 0.01 \mathrm{aB}$ & $2.1 \pm 1.0 \mathrm{aA}$ & $16.95 \pm 2.1 \mathrm{aB}$ & $1.7 \pm 1.3 \mathrm{aA}$ \\
\hline low & $5.1 \pm 0.3 \mathrm{bB}$ & $2.2 \pm 0.2 \mathrm{bA}$ & $52.7 \pm 2.3 \mathrm{bB}$ & $0.3 \pm 0.0 \mathrm{aA}$ & $1.0 \pm 0.1 \mathrm{aB}$ & $0.1 \pm 0 \mathrm{aB}$ & $2.1 \pm 0.7 \mathrm{aA}$ & $29.85 \pm 0.2 \mathrm{bB}$ & $2.9 \pm 1.5 \mathrm{aA}$ \\
\hline moderate & $5.2 \pm 0.3 \mathrm{bB}$ & $3.3 \pm 1.9 \mathrm{cB}$ & $61.9 \pm 11.2 \mathrm{bB}$ & $0.3 \pm 0.0 \mathrm{aA}$ & $1.0 \pm 0.0 \mathrm{aA}$ & $0.1 \pm 0.02 \mathrm{aA}$ & $3.4 \pm 1.5 \mathrm{aB}$ & $23.39 \pm 8.5 \mathrm{bB}$ & $2.5 \pm 1.2 \mathrm{aA}$ \\
\hline high & $3.0 \pm 0.4 \mathrm{aA}$ & $4.4 \pm 0.5 \mathrm{~dB}$ & $79.4 \pm 6.03 \mathrm{cB}$ & $0.3 \pm 0.0 \mathrm{aA}$ & $0.9 \pm 0.1 \mathrm{aA}$ & $0.1 \pm 0 \mathrm{aA}$ & $1.4 \pm 0.9 \mathrm{aA}$ & $11.74 \pm 4.0 \mathrm{aB}$ & $1.9 \pm 0.7 \mathrm{aA}$ \\
\hline
\end{tabular}

Values are means \pm SE $(n=6)$. For each species, different lower case letters indicate significant differences among treatments and different capital letters indicate significant differences among species undergoing the same treatment, according to Tukey's test $(P \leq 0.05)$

${ }^{\text {a }}$ salinity levels were assigned as none (no $\mathrm{NaCl}$ applied), low $(200 \mathrm{mM} \mathrm{NaCl})$, moderate $(400 \mathrm{mM} \mathrm{NaCl})$ and high $(600 \mathrm{mM} \mathrm{NaCl})$

${ }^{\mathrm{b}}$ Active compounds, ${ }^{\mathrm{c}}$ Deactivated compounds, ${ }^{\mathrm{d}}$ Oxidized compounds, ${ }^{\mathrm{e}}$ Conjugates, ${ }^{\mathrm{f}}$ Intermediate compounds

significantly decreased in both species under salinity.

The decline was more pronounced in A. tripolium (ACC concentration 2-3 times lower in stressed than in the control plants), than in A. alpinus (1.5-fold decrease) (Table 2).
Benzoic and salicylic acid

Under low and moderate salinity, the content of benzoic acid (BA) was the same as in control conditions, with total BA content higher in A. tripolium than in

Table 2 The content of endogenous stress-related phytohormones in A. tripolium and A. alpinus subjected to salinity

\begin{tabular}{|c|c|c|c|c|c|}
\hline \multirow{3}{*}{ Salinity level ${ }^{\mathrm{a}}$} & \multicolumn{5}{|c|}{ Endogenous phytohormones (nmol.g $\left.{ }^{-1} \mathrm{DW}\right)$} \\
\hline & \multicolumn{2}{|c|}{ Abscisic acid } & \multicolumn{2}{|c|}{ Jasmonates } & \multirow{2}{*}{$\begin{array}{l}\text { Ethylene precursor } \\
\text { ACC }\end{array}$} \\
\hline & $A c t v^{\mathrm{b}}$ & Deact ${ }^{\mathrm{c}}$ & Actv & Precursor & \\
\hline \multicolumn{6}{|l|}{ A. tripolium } \\
\hline none & $53.3 \pm 6.4 \mathrm{bB}$ & $8.7 \pm 1.9 \mathrm{bA}$ & $11.2 \pm 1.0 \mathrm{bA}$ & $1.1 \pm 0.0 \mathrm{aA}$ & $228.3 \pm 54.1 \mathrm{bA}$ \\
\hline low & $27.3 \pm 2.9 \mathrm{aA}$ & $6.4 \pm 1.0 \mathrm{bA}$ & $4.8 \pm 0.1 \mathrm{aA}$ & $1.6 \pm 0.5 \mathrm{bA}$ & $64.4 \pm 24.2 \mathrm{aA}$ \\
\hline moderate & $30.9 \pm 1.7 \mathrm{aA}$ & $7.4 \pm 0.2 \mathrm{bA}$ & $1.3 \pm 0.0 \mathrm{aA}$ & $1.5 \pm 0.2 \mathrm{bA}$ & $61.0 \pm 45.8 \mathrm{aA}$ \\
\hline high & $48.6 \pm 13.3 \mathrm{bB}$ & $4.8 \pm 2.5 \mathrm{aA}$ & $0.5 \pm 0.2 \mathrm{aA}$ & $2.4 \pm 0.8 \mathrm{bA}$ & $97.7 \pm 57.0 \mathrm{aA}$ \\
\hline \multicolumn{6}{|l|}{ A. alpinus } \\
\hline none & $11.0 \pm 0.4 \mathrm{aA}$ & $16.4 \pm 1.2 \mathrm{bB}$ & $9.6 \pm 3.1 \mathrm{bA}$ & $0.8 \pm 0.3 \mathrm{aA}$ & $313.8 \pm 59.7 \mathrm{bA}$ \\
\hline low & $26.2 \pm 0.7 \mathrm{bA}$ & $14.6 \pm 0.1 \mathrm{bB}$ & $1.1 \pm 0.3 \mathrm{aA}$ & $1.6 \pm 0.4 \mathrm{bA}$ & $170.5 \pm 35.8 \mathrm{aB}$ \\
\hline moderate & $20.5 \pm 5.6 \mathrm{bA}$ & $11.2 \pm 5.4 \mathrm{bA}$ & $1.0 \pm 0.3 \mathrm{aA}$ & $1.7 \pm 0.1 \mathrm{bA}$ & $193.5 \pm 55.5 \mathrm{aB}$ \\
\hline high & $14.4 \pm 1.4 \mathrm{aA}$ & $6.3 \pm 0.8 \mathrm{aA}$ & $0.9 \pm 0.1 \mathrm{aA}$ & $1.7 \pm 0.1 \mathrm{bA}$ & $208.7 \pm 46.2 \mathrm{abB}$ \\
\hline
\end{tabular}

Values are means $\pm \operatorname{SE}(n=6)$. For each species, different lower case letters indicate significant differences among treatments and different capital letters indicate significant differences among species undergoing the same treatment, according to Tukey's test $(P \leq 0.05)$

${ }^{\text {a }}$ salinity levels were assigned as none (no $\mathrm{NaCl}$ applied), low $(200 \mathrm{mM} \mathrm{NaCl})$, moderate $(400 \mathrm{mM} \mathrm{NaCl})$ and high $(600 \mathrm{mM} \mathrm{NaCl})$

${ }^{\mathrm{b}}$ Active compounds, ${ }^{\mathrm{c}}$ Deactivated compounds, 
A. alpinus (Fig. 1a). In high salinity conditions it decreased in A. tripolium and increased in A. alpinus, so final BA concentration in A. alpinus was higher than in A. tripolium. Salicylic acid (SA) content rose in A. alpinus at all salinity levels (regardless of its intensity), while in A. tripolium SA accumulation significantly dropped at low and moderate salinity levels (Fig. 1b). In salt-treated A. alpinus the content of SA was higher than in respective A. tripolium plants. Considering the entire pool of growth-regulating compounds, it is noteworthy that the changes in BA and SA contents, together with distinct pattern of active ABA accumulation, were the parameters that clearly diversified responses to salinity between the studied species.

Growth parameters and chlorophyll content

The stem length (SL), expressed as a percentage of respective untreated controls, decreased in both studied species exposed to salinity. Average SL reduced about 35 to $60 \%$ and 43 to $73 \%$ of the control in A. tripolium and $A$. alpinus, respectively (Table $3 a$ ).

Reduction of water content (WC) in the leaves was more pronounced in salt-sensitive A. alpinus than in A. tripolium. Under low, moderate and high salinity water content loss in the leaves of A. alpinus was $6 \%$, $23 \%$ and $27 \%$, respectively, in comparison with control plants. In A. tripolium, WC\% decreased significantly only at high salinity (Table $3 \mathrm{~b}$ ).

Growth Tolerance Index (GTI) (calculated on the basis of DW) for shoots exposed to low, moderate and high salinity amounted to 99,82 and $83 \%$, respectively, in A. tripolium, and to 59, 67 and $70 \%$ in A. alpinus. In A. alpinus differences in GTI between salinity levels were statistically insignificant (Table 3c).

Chlorophyll content $(\mathrm{Chl})$ was here considered a parameter that reflected plant photosynthetic capacity and species ability to sustain growth under stress.
Fig. 1 Organic acids content in two Asteraceae species subjected to salinity. Benzoic acid (BA) (a), salicylic acid (SA) (b) content in leaves of two Asteraceae species, after 4 weeks of salt treatments of exposure to low, moderate and high salinity. Values are means $\pm \mathrm{SE}(n=6)$. For each species, different lower case letters indicate significant differences among treatments and different capital letters indicate significant differences among species undergoing the same treatment, according to ANOVA and post hoc Tukey's test $(P \leq 0.05)$ a)

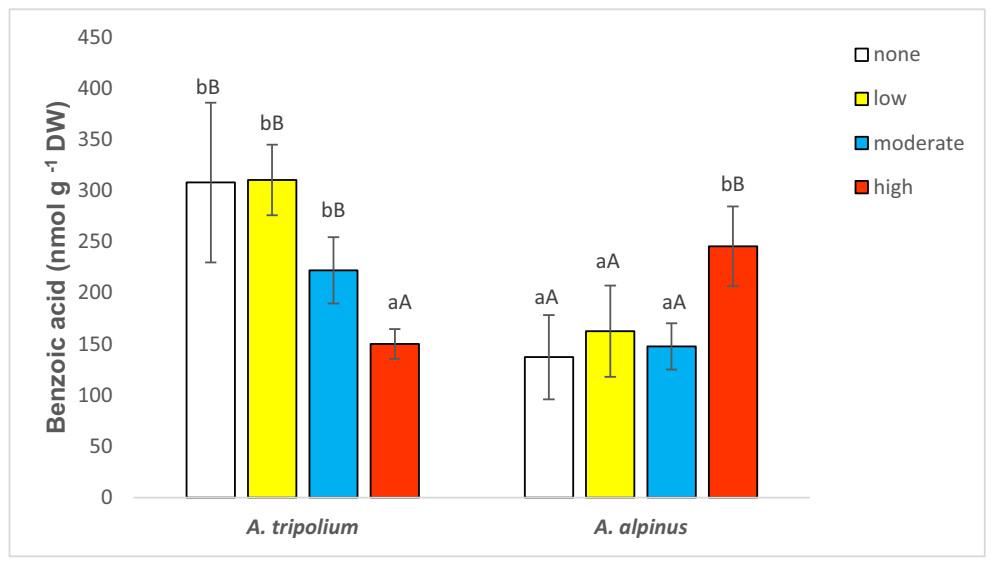

b)

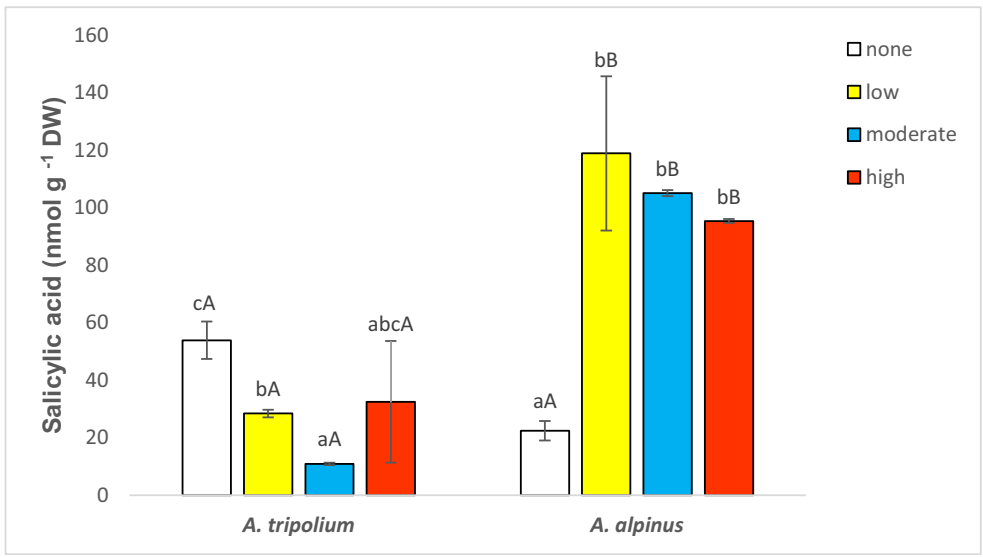


Table 3 Growth parameters and chlorophyll content in A. tripolium and A. alpinus subjected to salinity

\begin{tabular}{|c|c|c|c|}
\hline \multirow[t]{2}{*}{ Parameter } & \multirow[t]{2}{*}{ Salinity treatments ${ }^{\mathrm{a}}$} & \multicolumn{2}{|l|}{ Species } \\
\hline & & A. tripolium & A. alpinus \\
\hline \multirow{4}{*}{$\begin{array}{l}\text { (a) } \\
\text { Stem length ( } \% \text { of control) }\end{array}$} & none & $100 \pm 3 \mathrm{cA}$ & $100 \pm 3.61 \mathrm{cA}$ \\
\hline & low & $65.85 \pm 4.58 \mathrm{bA}$ & $57.14 \pm 2.29 \mathrm{bA}$ \\
\hline & moderate & $52.85 \pm 3.51 \mathrm{bA}$ & $44.44 \pm 1.53 \mathrm{bA}$ \\
\hline & high & $39.02 \pm 3.61 \mathrm{aB}$ & $27.14 \pm 0.44 \mathrm{aA}$ \\
\hline \multirow{4}{*}{$\begin{array}{l}\text { (b) } \\
\text { WC\% in leaves }\end{array}$} & none & $84.98 \pm 0.36 \mathrm{bA}$ & $70.89 \pm 6.68 \mathrm{cA}$ \\
\hline & low & $86.95 \pm 1.11 \mathrm{bB}$ & $65.22 \pm 13.43 \mathrm{bA}$ \\
\hline & moderate & $80.21 \pm 3.49 \mathrm{bB}$ & $47.67 \pm 5.65 \mathrm{aA}$ \\
\hline & high & $63.24 \pm 9.74 \mathrm{aB}$ & $43.65 \pm 5.27 \mathrm{aA}$ \\
\hline \multirow{4}{*}{$\begin{array}{l}\text { (c) } \\
\text { GTI shoots }\end{array}$} & none & 100 & 100 \\
\hline & low & $99.32 \mathrm{bA}$ & $59.53 \mathrm{aB}$ \\
\hline & moderate & $82.46 \mathrm{aA}$ & $66.98 \mathrm{aB}$ \\
\hline & high & $82.93 \mathrm{aA}$ & $69.78 \mathrm{aB}$ \\
\hline \multirow{4}{*}{$\mathrm{Chl}_{\mathrm{a}+\mathrm{b}}\left(\mathrm{mg} \cdot \mathrm{g}^{-1} \mathrm{DW}\right)$} & none & $8.95 \pm 0.03 \mathrm{~dB}$ & $6.54 \pm 0 \mathrm{cA}$ \\
\hline & low & $7.4 \pm 0.15 \mathrm{cB}$ & $1.57 \pm 0.01 \mathrm{bA}$ \\
\hline & moderate & $4.38 \pm 0.31 \mathrm{bB}$ & $0.25 \pm 0.11 \mathrm{aA}$ \\
\hline & high & $1.24 \pm 0.03 \mathrm{aB}$ & $0.22 \pm 0.05 \mathrm{aA}$ \\
\hline
\end{tabular}

$\overline{\text { Values are means } \pm \mathrm{SE}(n=3) \text {. For each species, different lower case letters indicate significant differences among treatments and different }}$ capital letters indicate significant differences among species undergoing the same treatment, according to one-way ANOVA and post hoc Tukey's test $(\mathrm{P} \leq 0.05)$

${ }^{\text {a }}$ salinity levels were assigned as none (no $\mathrm{NaCl}$ applied), low $(200 \mathrm{mM} \mathrm{NaCl})$, moderate $(400 \mathrm{mM} \mathrm{NaCl})$ and high $(600 \mathrm{mM} \mathrm{NaCl})$

Salinity reduced the leaf content of chlorophylls $(a+b)$ in both Aster species, but more pronounced decrease was detected in salt-treated A. alpinus. Under low salinity, the decline reached 18 and $76 \%$, while under high salinity 86 and $90 \%$ in A. tripolium and A. alpinus, respectively (Table $3 \mathrm{~d}$ ).

\section{Correlations between growth parameters and changes in PGR content}

Correlations between data on growth parameters and on phytohormones were identified using a correlation matrix. Several differences in correlating parameters were observed between the studied species (Fig. 2). On the Fig. 2 PGRs that were predominantly correlated with studied parameters in halophyte A. tripolium were colored blue, while those that were mainly correlated with the parameters determined in glycophyte A. alpinus were colored red.

In halophyte stem length (SL), water content percentage (WC\%) and total chlorophylls (Chl) positively correlated with BA content, and SL and Chl also with JA content. Majority of growth parameters negatively correlated with total GA pool, and $\mathrm{WC} \%$ and Chl also with Cyt and Aux. Only GTI positively correlated with the changes in SA content.

In turn, in glycophyte all growth parameters (SL, WC\%, GTI, Chl) negatively correlated with the contents of salicylic acid (SA) and ACC (ethylene precursor).

Ion accumulation

Sodium and chloride levels increased in the roots and leaves of both species, in parallel with increasing external salinity, in comparison with the control conditions. A. tripolium accumulated more $\mathrm{Na}^{+}$in its organs than A. alpinus (Fig. 3a). In the roots treated with low, moderate and high salinity A. alpinus accumulated 16, 26 and $40 \mathrm{~g} \cdot \mathrm{kg}^{-1} \mathrm{DW}$, respectively, as compared with 22,51 and $74 \mathrm{~g} \cdot \mathrm{kg}^{-1} \mathrm{DW}$ determined for A. tripolium. A similar trend was observed in the leaves. In A. tripolium roots, $\mathrm{Na}^{+}$concentrations in the control and under low salinity were similar $(P>0.05)$. Interestingly, the initial $\mathrm{Na}^{+}$content in A. alpinus was 4.5 times and 7 times 


\begin{tabular}{|c|c|c|c|c|c|}
\hline & & \multicolumn{2}{|c|}{ Halophyte Aster tripolium } & \multicolumn{2}{|c|}{ Glycophyte Aster alpinus } \\
\hline & & $(+)$ & $(-)$ & $(+)$ & $(-)$ \\
\hline \multirow{4}{*}{$\begin{array}{l}\text { Growth } \\
\text { performance }\end{array}$} & SL & $\mathrm{BA}, \mathrm{JA}$ & GA & & $\mathrm{SA}, \mathrm{ACC}$ \\
\hline & $\mathrm{WC} \%$ & BA & GA, Aux, Cyt & & $\mathrm{SA}, \mathrm{ACC}$ \\
\hline & GTI & SA & & & SA, ACC \\
\hline & $\mathrm{Chl}$ & $\mathrm{BA}, \mathrm{JA}$ & GA, Aux, Cyt & & $\mathrm{SA}, \mathrm{ACC}$ \\
\hline \multirow[t]{9}{*}{ Osmolytes } & Pro & GA & $\mathrm{BA}, \mathrm{JA}$ & & \\
\hline & GlyB & GA & BA, JA & & BA \\
\hline & ProB & GA, Aux, Cyt & BA & $\mathrm{ABA}, \mathrm{ACC}$ & \\
\hline & TSC & BA, Cyt, GA & Aux & $\mathrm{ABA}$ & Cyt, GA \\
\hline & SuAlc & GA & $\mathrm{JA}, \mathrm{BA}$ & GA, BA, Cyt, ABA & \\
\hline & Oligo & JA & GA & & \\
\hline & Fruct & JA & GA & & \\
\hline & Mono \& Di & GA & $\mathrm{JA}, \mathrm{BA}$ & $\mathrm{SA}, \mathrm{ACC}$ & \\
\hline & UA & & SA & & Cyt, GA, ABA \\
\hline \multirow[t]{6}{*}{ Ions } & Na Leaf & Cyt, Aux, GA & $\mathrm{JA}, \mathrm{BA}$ & & \\
\hline & Na Root & Cyt, Aux, GA & JA, BA & & \\
\hline & $\mathrm{Cl}$ Leaf & Cyt, GA & JA, BA & & Cyt, GA, ABA, SA \\
\hline & $\mathrm{Cl}$ Root & Cyt, Aux, GA & JA, BA & & Cyt, GA, ABA, SA \\
\hline & K Leaf & $\mathrm{JA}, \mathrm{BA}$ & Cyt, GA & & $\mathrm{ACC}$ \\
\hline & K Root & $\mathrm{JA}, \mathrm{BA}$ & Cyt, Aux, GA & & $\mathrm{ACC}$ \\
\hline \multirow{6}{*}{$\begin{array}{l}\text { Antioxidant } \\
\text { machinery }\end{array}$} & MDA & Cyt, Aux, GA & $\mathrm{BA}$ & & SA, ACC \\
\hline & POD & & Cyt, Aux, GA & Cyt, GA, ABA, SA & \\
\hline & CAT & & Cyt, GA & & \\
\hline & TPC & & $\mathrm{JA}, \mathrm{BA}$ & & $\mathrm{ACC}$ \\
\hline & $\mathrm{FV}$ & $\mathrm{JA}, \mathrm{BA}$ & SA & $\mathrm{ACC}, \mathrm{SA}$ & \\
\hline & Car & & $\mathrm{JA}, \mathrm{BA}$ & & $\mathrm{ACC}$ \\
\hline
\end{tabular}

Fig. 2 Significant correlations $(>0.75,<-0.75)$ between the changes in endogenous PGRs content and determined biometrical and biochemical parameters in halophyte A. tripolium (blue) and glycophyte A. alpinus (red) under progressive salinity

lower in the roots and the leaves, respectively, in comparison with control A. tripolium plants (Fig. 3a).

Chloride content at respective salinity levels was always lower in A. alpinus than in A. tripolium. Also, initial $\mathrm{Cl}^{-}$concentrations were lower in A. alpinus roots ( $\sim 2$ - fold) and leaves ( 3-fold), as compared with A. tripolium. $\mathrm{Cl}^{-}$content in A. tripolium roots remained at the control level at low salinity. In turn, in the roots of A. alpinus similar accumulation of $\mathrm{Cl}^{-}$was noted at moderate and high salinity (Fig. 3b).

Potassium content in A. tripolium roots was stable under low and moderate salinity, and declined significantly at high salinity. In A alpinus roots $\mathrm{K}^{+}$content increased at low salinity, while at moderate and high stress it was at the same level as in control plants (Fig. $3 \mathrm{c})$. Similarly to $\mathrm{Na}^{+}$, the initial $\mathrm{K}^{+}$content in the organs of control plants was significantly higher in A. tripolium than in A. alpinus (37.63 vs. $21.2 \mathrm{~g} \cdot \mathrm{kg}^{-1} \mathrm{DW}$ in the roots and $72.44 \mathrm{vs} .45 .3 \mathrm{~g} \cdot \mathrm{kg}^{-1} \mathrm{DW}$ in the leaves, respectively). The studied species differed also in a pattern of $\mathrm{K}^{+}$ accumulation in the leaves. In A. tripolium $\mathrm{K}^{+}$content decreased in parallel with increasing salinity, while in A. alpinus it remained unaffected (Fig. 3c). Due to significant and progressive reduction of $\mathrm{K}^{+}$content in
A. tripolium leaves, its concentration at high salinity reached about $50 \%$ of the control (Fig. 3c). However, it was still higher than in any of A. alpinus leaves.

The $\mathrm{K}^{+} / \mathrm{Na}^{+}$ratio, which is considered a parameter relevant for maintaining ionic homeostasis, generally decreased in the leaves and the roots of both species under salinity conditions, with an exception of A. tripolium roots exposed to low salinity (Fig. 3d). Initially the ratio was higher in A. alpinus than in A. tripolium, and reductions caused by salinity were also more pronounced in A. alpinus.

\section{Correlations between ion content and changes in PGR content}

In halophyte sodium and chloride contents in plant organs positively correlated with total Cyt, Aux and GA pools, and negatively with JA and BA content. A reverse pattern of correlations was found in the case of potassium ions - a positive correlation with JA and BA, and negative with Cyt, Aux and GA concentrations (Fig. 2).

In glycophyte sodium concentrations in plant organs did not correlate with the content of any PGR, whereas 
a)

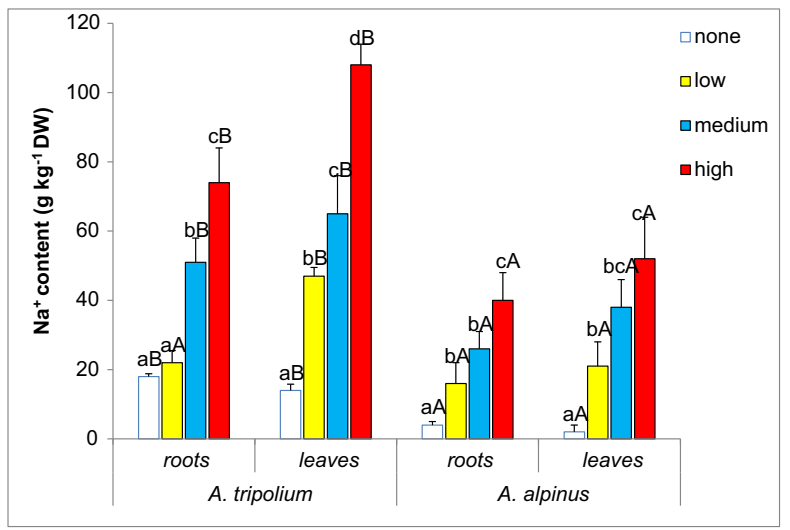

b)

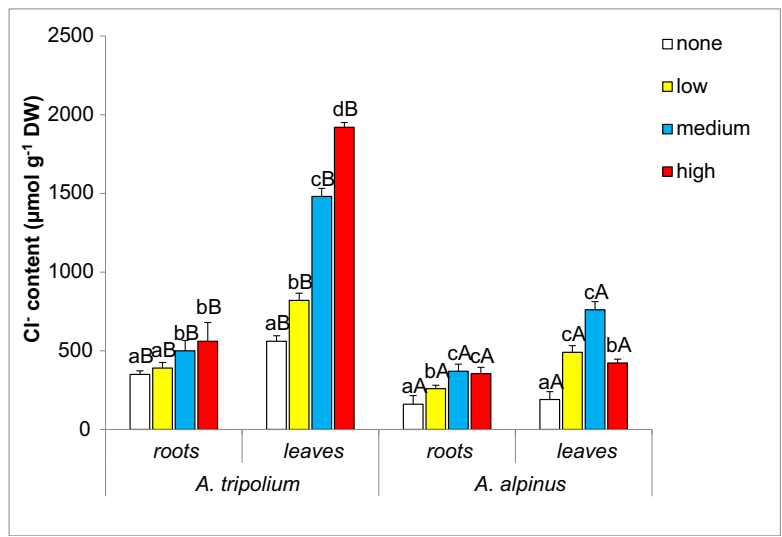

Fig. 3 Ion accumulation in two Asteraceae species subjected to salinity. Sodium $\left(\mathrm{Na}^{+}\right)(\mathbf{a})$, chloride $\left(\mathrm{Cl}^{-}\right)(\mathbf{b})$, potassium $\left(\mathrm{K}^{+}\right)(\mathbf{c})$ concentrations and $\mathrm{K}^{+} / \mathrm{Na}^{+}$ratio (d) in leaves and roots of two Asteraceae species, after 4 weeks of exposure to low, moderate and high salinity. Values are means $\pm \operatorname{SE}(n=6)$. For each species,

chloride accumulation negatively correlated with the contents of Cyt, GA, ABA and SA. Potassium content negatively correlated with the level of ACC (Fig. 2).

Accumulation of osmolytes: osmoprotectant amino acids

Proline (Pro) content increased under salinity in both species, however, a 2-fold higher increment was recorded in A. alpinus than in A. tripolium under the highest salinity $\left(2056 \mu \mathrm{g} \cdot \mathrm{g}^{-1} \mathrm{DW}\right.$ and $1083 \mu \mathrm{g} \cdot \mathrm{g}^{-1} \mathrm{DW}$ respectively). The initial Pro content was similar in both species (Table 4).

Regarding glycine betaine (GlyB) accumulation, no clear trend was found in any of the studied species. In A. tripolium, an increase in GlyB was observed at low salinity, no changes at moderate c)

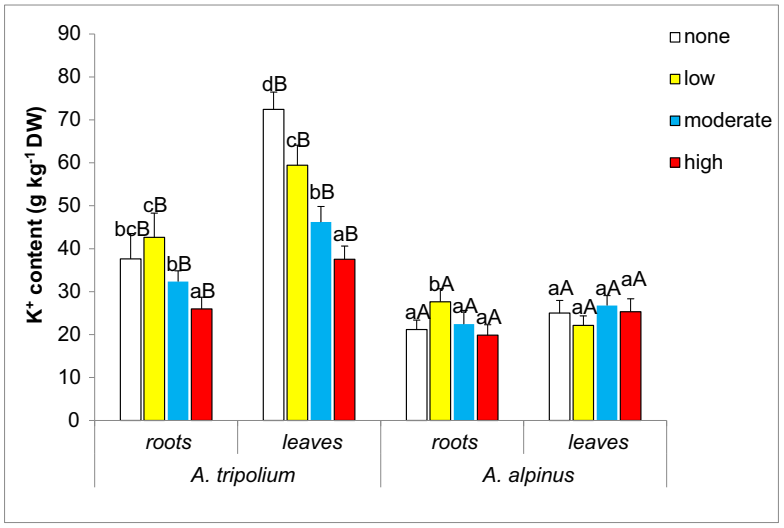

d)

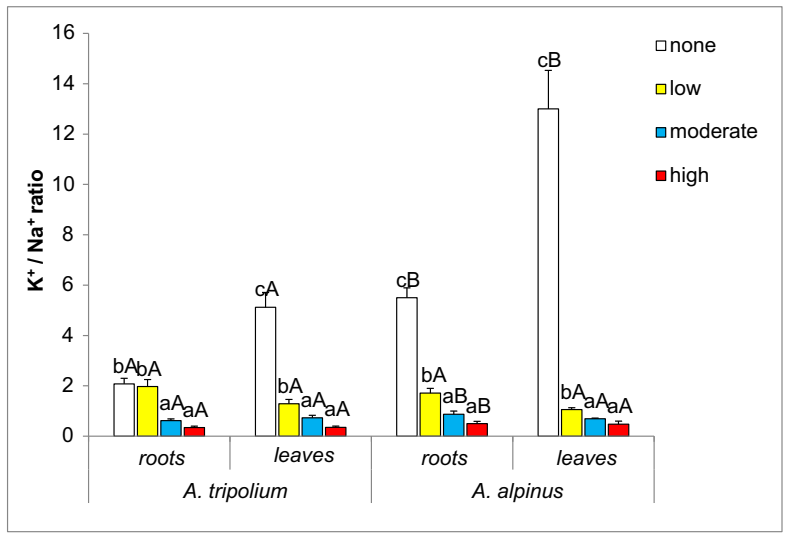

different lower case letters indicate significant differences among treatments and different capital letters indicate significant differences among species undergoing the same treatment, according to ANOVA and post hoc Tukey's test $(\mathrm{P} \leq 0.05)$

one and a slight decrease at high stress level (Table 4). In A. alpinus, a decline in GlyB content was recorded under all applied salinity levels, and it was more pronounced under low and moderate salinity than under the high one. The initial GlyB level was over 3 -fold higher in A. alpinus than in A. tripolium (Table 4).

Proline betaine (ProB) content was very low (not exceeding $2 \mu \mathrm{g} \cdot \mathrm{g}^{-1} \mathrm{DW}$ ) in A. tripolium and no significant changes were observed under salt exposure. Contrary to that, in A. alpinus a drastic increment of this amino acid content was noted (303, 321 and $1106 \mu \mathrm{g} \cdot \mathrm{g}^{-1} \mathrm{DW}$ under low, moderate and high salinity, respectively) in comparison with $3 \mu \mathrm{g} \cdot \mathrm{g}^{-1} \mathrm{DW}$ in the control (Table 4). ProB was the only amino acid whose content changed differently under salinity in the studied species. 
Table 4 Proline (Pro), glycine betaine (GlyB), proline betaine (ProB) concentrations in two Asteraceae species subjected to salinity

\begin{tabular}{|c|c|c|c|}
\hline \multirow[t]{2}{*}{ Salinity level $^{\mathrm{a}}$} & \multicolumn{3}{|c|}{ Osmoprotectant amino acids $\left(\mu \mathrm{g} \cdot \mathrm{g}^{-1} \mathrm{DW}\right)$} \\
\hline & Pro & GlyB & ProB \\
\hline \multicolumn{4}{|l|}{ A. tripolium } \\
\hline none & $41.7 \pm 13.2 \mathrm{aA}$ & $1199.5 \pm 206.8 \mathrm{bA}$ & $1.4 \pm 0.0 \mathrm{aA}$ \\
\hline low & $508.8 \pm 116.1 \mathrm{bA}$ & $2192.4 \pm 361.3 \mathrm{cB}$ & $1.2 \pm 0.0 \mathrm{aA}$ \\
\hline moderate & $1014.3 \pm 111.6 \mathrm{cA}$ & $1169.0 \pm 234.9 \mathrm{bA}$ & $1.4 \pm 0.0 \mathrm{aA}$ \\
\hline high & $1083.0 \pm 289.9 \mathrm{cA}$ & $689.5 \pm 126.7 \mathrm{aA}$ & $1.9 \pm 1.6 \mathrm{aA}$ \\
\hline \multicolumn{4}{|l|}{ A. alpinus } \\
\hline none & $79.3 \pm 32.56 \mathrm{aA}$ & $3590.8 \pm 126.7 \mathrm{cB}$ & $3.2 \pm 0.1 \mathrm{aA}$ \\
\hline low & $1132.2 \pm 57 \mathrm{bB}$ & $1541.9 \pm 238.8 \mathrm{aA}$ & $303.2 \pm 9.6 \mathrm{bB}$ \\
\hline moderate & $986.8 \pm 151.30 \mathrm{bA}$ & $1187.8 \pm 224.1 \mathrm{aA}$ & $321.6 \pm 10.7 \mathrm{bB}$ \\
\hline high & $2056.9 \pm 59.75 \mathrm{cB}$ & $2833.3 \pm 95.5 \mathrm{bB}$ & $1106.9 \pm 12.9 \mathrm{bB}$ \\
\hline
\end{tabular}

Values are means \pm SE, $(n=6)$. For each species, different lower case letters indicate significant differences among treatments and different capital letters indicate significant differences among species undergoing the same treatment, according to ANOVA and post hoc Tukey's test $(\mathrm{P} \leq 0.05)$

${ }^{\text {a }}$ salinity levels were assigned as none (no $\mathrm{NaCl}$ applied), low (200 $\left.\mathrm{mM} \mathrm{NaCl}\right)$, moderate $(400 \mathrm{mM} \mathrm{NaCl})$ and high $(600 \mathrm{mM} \mathrm{NaCl})$

Correlations between the content of osmoprotectant amino acids and PGRs

In halophyte the concentrations of all determined amino acids (Pro, GlyB, ProB) negatively correlated with BA content, and Pro and GlyB also with JA. A positive correlation occurred between the contents of all amino acids and GA. Additionally, ProB content positively correlated with Aux and Cyt (Fig. 2).

In glycophyte GlyB content negatively correlated with changes in BA level, while ProB correlated positively with ABA and ACC content. Changes in Pro levels did not correlate with any changes in the profile of endogenous PGRs (Fig. 2).

Accumulation of osmolytes: carbohydrates

In investigated species total soluble carbohydrate (TSC) content was affected by salinity in distinct manner. In A. tripolium, TSC decreased under high salinity, and did not change under low and moderate salinity. In A. alpinus TSC increased in salinity conditions in comparison with the control, regardless of stress intensity (Fig. 4a). TSC content differed between A. tripolium and A. alpinus only at high salinity, where it was higher in the latter species (Fig. 4a).

\section{Oligosaccharides}

Total pool of oligosaccharides, including fructans, decreased under salinity in both studied species. Interestingly, the initial concentrations of these compounds were considerably higher in A. alpinus than in $A$. tripolium. Oligosaccharides amounted to 12.33 and $13.23 \mu \mathrm{g} \cdot \mathrm{mg}^{-1} \mathrm{DW}$ in A. tripolium and A. alpinus, respectively, while the levels of fructans reached 4.17 and $6.39 \mu \mathrm{g} \cdot \mathrm{mg}^{-1} \mathrm{DW}$ (data not shown).

\section{Sugar alcohols}

In A. alpinus salinity did not change the content of sugar alcohols, which was considerably low (about $3 \mu \mathrm{g} \cdot \mathrm{mg}^{-1}$ DW) (Fig. 4c). Contrary to that, A. tripolium responded to salinity with massive accumulation of sugar alcohols. The content of these compounds increased to 18.5 $26.8 \mu \mathrm{g} \cdot \mathrm{mg}^{-1} \mathrm{DW}$, in comparison with $5.2 \mu \mathrm{g} \cdot \mathrm{mg}^{-1}$ DW in control plants $(P<0.05)$. Polyol content was the carbohydrate profile parameter that diversified responses to salinity in the studied species.

\section{Mono- and disaccharides}

A clear salinity-dependent increase in glucose and fructose accumulation was only detected in A. alpinus, whereas in A. tripolium changes in the concentrations 
a)

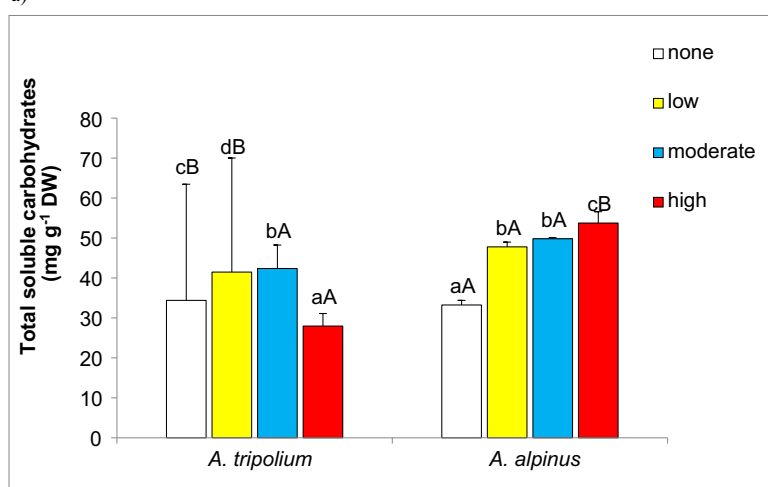

b)

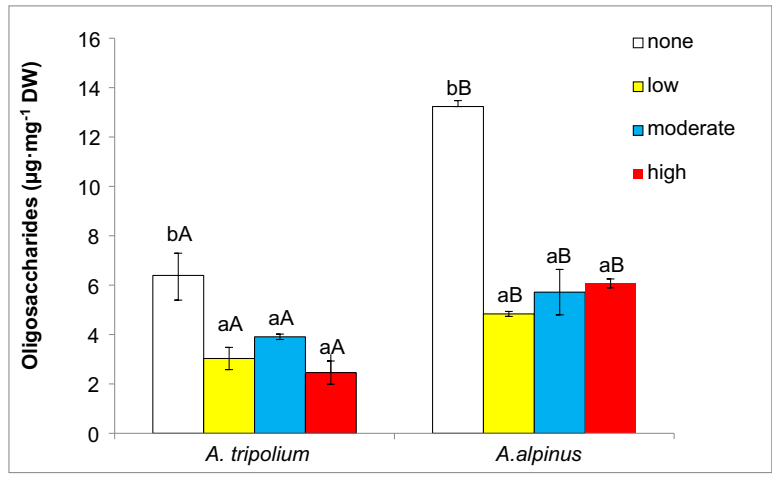

c)

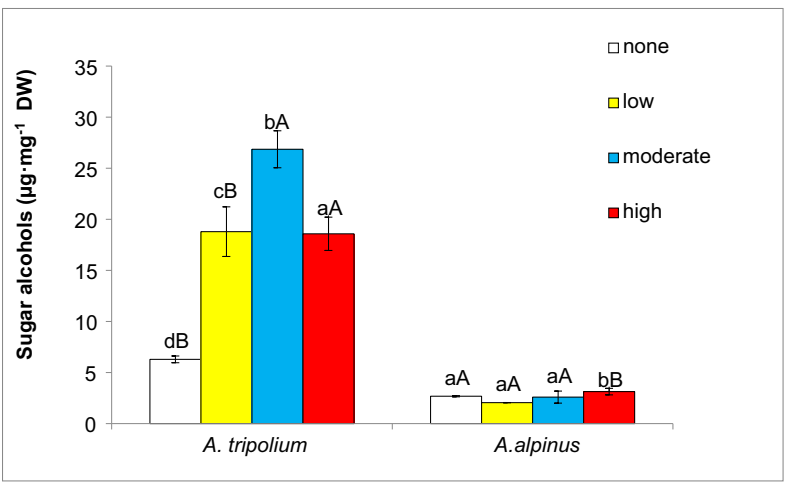

d)

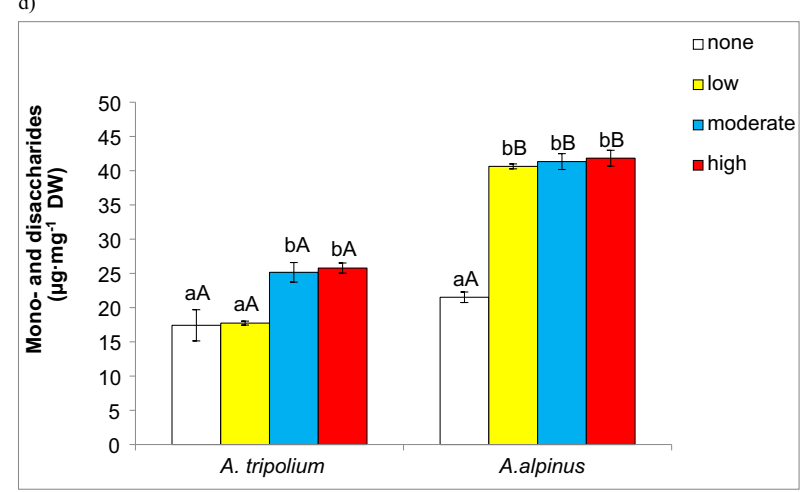

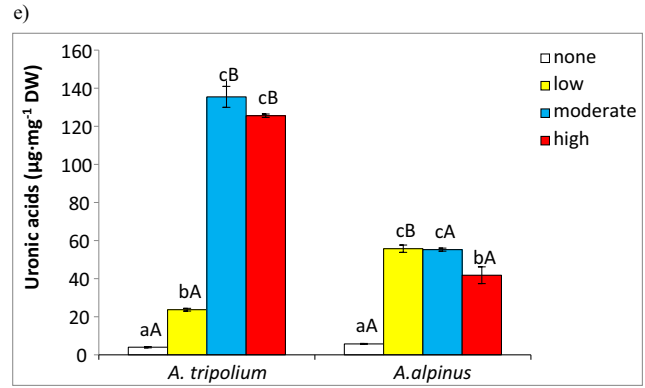

Fig. 4 Carbohydrate profile in two Asteraceae species subjected to salinity. Content of total soluble carbohydrates (TSC) (a), oligosaccharides (b), sugar alcohols (c), mono- and disaccharides (d) and uronic acids (e) in two Asteraceae species, after 4 weeks of exposure to low, moderate and high salinity. Values are means

of both sugars were statistically insignificant (data not shown). Regarding sucrose, a considerable increase was detected in A. tripolium under moderate and high salinity, whereas in A. alpinus sucrose content drastically increased under low salinity and decreased under moderate and high one (data not shown). Maltose content was mostly affected by salinity treatment in A. alpinus (its levels dropped from $13.23 \mu \mathrm{g} \cdot \mathrm{mg}^{-1} \mathrm{DW}$ in control plants to $4.84-6.07 \mu \mathrm{g} \cdot \mathrm{mg}^{-1} \mathrm{DW}, \mathrm{P}<0.05$ ) (data not shown). Regarding total content of mono- and \pm SE $(n=6)$. For each species, different lower case letters indicate significant differences among treatments and different capital letters indicate significant differences among species undergoing the same treatment, according to ANOVA and post hoc Tukey's test $(P \leq 0.05)$

disaccharides, it increased in both species under salinity, with only exception of $A$. tripolium subjected to its low level (no change in comparison with untreated plants). Accumulation of these carbohydrates was more intense in A. alpinus than in A. tripolium (Fig. 4d).

\section{Uronic acids}

Concentrations of uronic acids (UA) in the control plants were relatively low and comparable in both 
a)

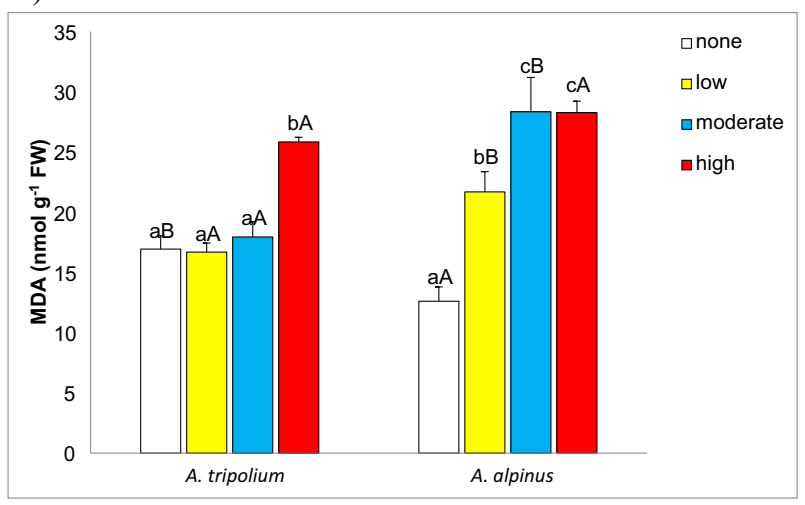

b)

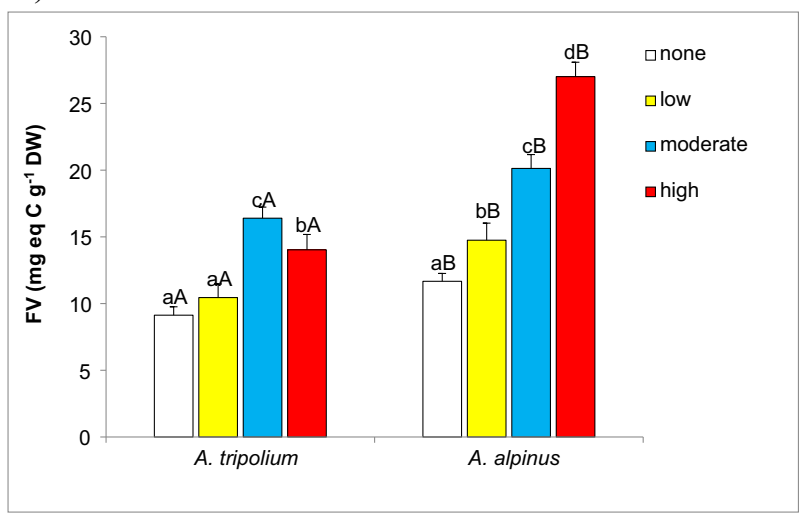

c)

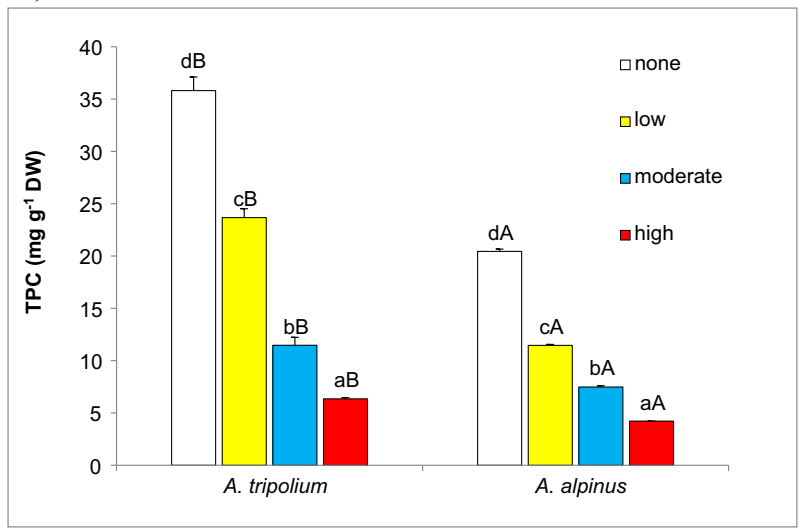

Fig. 5 Lipid peroxidation, a content of non-enzymatic antioxidants and antioxidant enzyme activity in two Asteraceae species subjected to salinity. Leaf malondialdehyde (MDA) (a), total flavonoids (FV) (b), total phenolic compounds (TPC) (c), carotenoids (Car) (d) contents, catalase activity (e) and peroxidase activity (f) in two Asteraceae species, after 4 weeks of exposure

studied species (Fig. 4e). Accumulation of these compounds accelerated in response to salinity. Particularly in A. tripolium, total UA level increased from $4 \mu \mathrm{g} \cdot \mathrm{mg}^{-1}$ d)

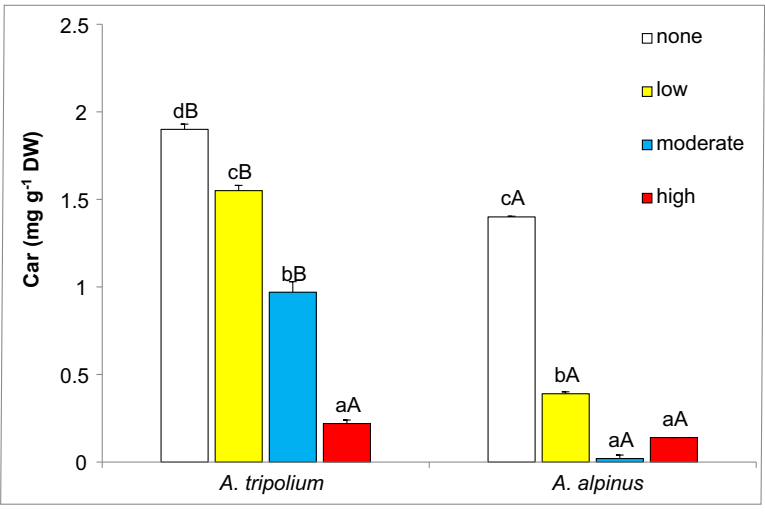

e)
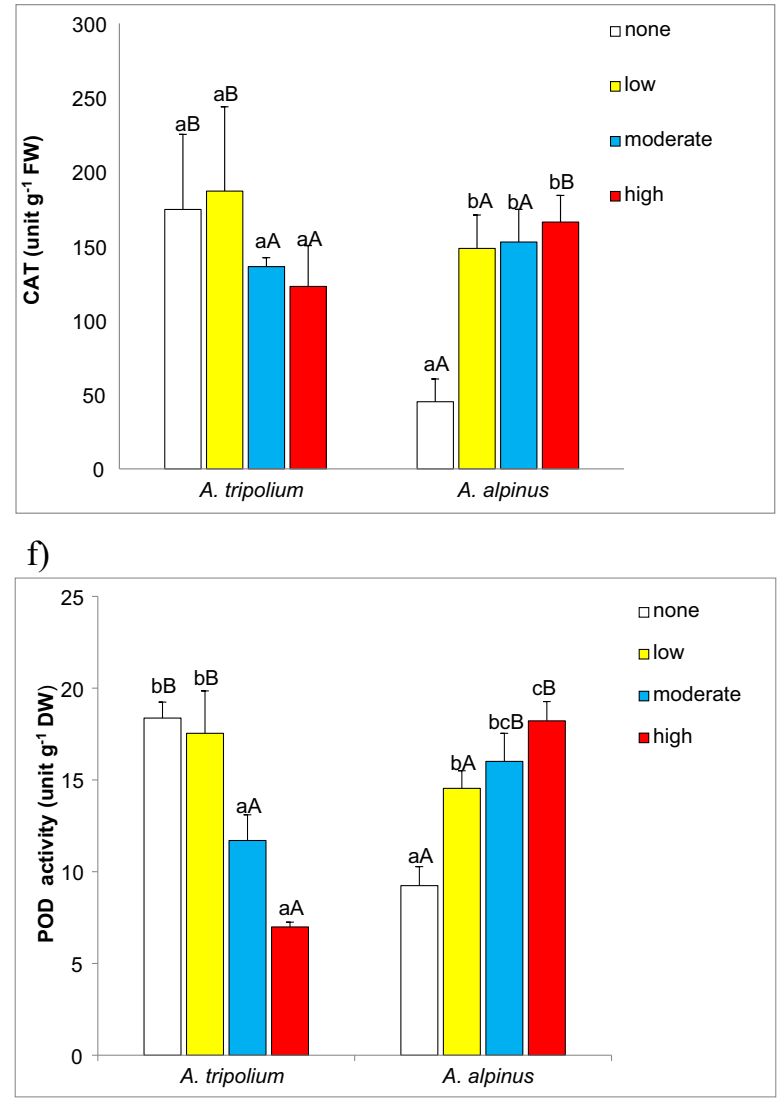

to low, moderate and high salinity. Values are means $\pm \operatorname{SE}(n=6)$. For each species, different lower case letters indicate significant differences among treatments and different capital letters indicate significant differences among species undergoing the same treatment, according to ANOVA and post hoc Tukey's test $(\mathrm{P} \leq 0.05)$

DW in control plants to 135.5 and $125.6 \mu \mathrm{g} \cdot \mathrm{mg}^{-1} \mathrm{DW}$ under moderate and high salinity, respectively (Fig. 4e). In A. alpinus, increments were not as high as in 
A. tripolium and reached $41.8-55.2 \mu \mathrm{g} \cdot \mathrm{mg}^{-1} \mathrm{DW}$ (Fig. 3e).

\section{Correlations between the content of carbohydrates and PGRs}

In halophyte TSC positively correlated with Cyt, GA and BA pools and negatively with Aux. Accumulation of oligosaccharides (Oligo) (including fructans (Fruc)) correlated positively with JA and negatively with total GA pool. Inverse correlations occurred for the content of sugar alcohols and mono- and disaccharides that correlated positively with GA and negatively with JA levels. The content of sugar alcohols (SuAlc) also negatively correlated with changes in BA content. Uronic acids (UA), massively accumulated in halophyte under salinity, negatively correlated with SA content (Fig. 2).

In glycophyte TSC negatively correlated with the contents of Cyt and GA, and positively with ABA. Positive correlation was also found between accumulation of sugar alcohols and changes in GA, Cyt, ABA and BA contents, as well as between the contents of mono- and disaccharides and SA and ACC. A negative correlation occurred between the contents of uronic acids and the pool of Cyt, GA and ABA (Fig. 2).

Oxidative stress level and antioxidant activity

In control conditions, malondialdehyde (MDA) concentration, reflecting oxidative stress level, was higher in A. tripolium than in A. alpinus. Under salinity, regardless of its level, MDA content increased significantly in A. alpinus, while in A. tripolium lipid peroxidation enhanced only under high salinity (Fig. 5a).

As for non-enzymatic antioxidants, both species increased their accumulation of total flavonoids (FV) under moderate and high salinity, and in case of A. alpinus at low salinity as well. The increase was more pronounced in A. alpinus and occurred at all salinity levels. In A. tripolium, significant increments in FV content occurred under moderate and high salinity (Fig. 5b). An inverse trend was observed for total phenolics (Fig. 5c) and carotenoids (Fig. 5d). In control conditions, A. tripolium had higher content of these compounds than A. alpinus. Salinity reduced TPC and Car accumulation in both species, with lower contents determined in A. alpinus than in A. tripolium under respective treatments (Fig. $5 \mathrm{~cd}$ ).
The studied species exhibited different patterns of two antioxidant enzymes activity in response to salinity. In A. alpinus, the enzymatic activity increased under salinity conditions, irrespectively of $\mathrm{NaCl}$ concentrations. CAT activity increased 3-fold and POD 1.5- fold in comparison with control plants (Fig. 5e, f). In A. tripolium, the activity of CAT did not change under salinity, whereas POD activity declined under moderate and high salinity by 36 and $62 \%$ respectively (Fig. 5 e, f).

\section{Correlations between the elements of antioxidant machinery and changes of PGRs content}

In halophyte the content of MDA correlated positively with total concentrations of Cyt, Aux and GA, and negatively with BA levels. Significant correlations between PGRs and elements of antioxidant machinery were also found. Both POD and CAT activity negatively correlated with total pool of Cyt and GA, and POD also correlated with Aux. The contents of nonenzymatic antioxidants, TPC and Car, correlated negatively with JA and BA levels, whereas FV content correlated positively with these two PGRs. Flavonoids also negatively correlated with SA content.

In glycophyte negative correlation was found between MDA content and the concentrations of SA and ACC. Considering the antioxidant system, POD activity correlated positively with total pool of Cyt, GA, ABA, and SA. In the case of CAT activity, no significant correlations with PGR content were detected. Concentrations of non-enzymatic antioxidants correlated with ACC accumulation: TPC and Car - negatively, and FV - positively. Additionally, changes in FV concentrations correlated positively with SA concentrations.

\section{Discussion}

Halophyte adaptation to salinity requires the interplay between three known defense mechanisms: maintaining of ion homeostasis, osmotic adjustment by synthesis of osmolytes, and effective neutralization of excessive reactive oxygen species (ROS) by antioxidant system (Soundararajan et al. 2019). The same mechanisms, although usually less pronounced, are activated in salt-sensitive glycophytes subjected to salt excess (Bartels and Dinakar 2013; Ellouzi et al. 2014; Gharbi et al. 2017; Shabala 2013). Differences between the 
responses of halophytes and glycophytes, resulting in salinity tolerance or its lack, can be conditioned by subtle variations in regulatory and signaling pathways, yet they are poorly understood. Recently, metabolomic profiling, including profiling of endogenous phytohormones, brought about new information on these aspects in salt-tolerant species (Benjamin et al. 2019; Kumari and Parida 2018; Wiszniewska et al. 2019). In this study, a comparative analysis of defense mechanisms under low, moderate and high salinity was aimed at correlating the changes in the level of several parameters, depicting defense mechanisms, with the changes occurring in the pools of major PGRs. This approach revealed that in halophytic and glycophytic Asteraceae species distinct regulatory compounds are responsible for developing defense response under salt exposure.

Ion uptake and maintaining ionic homeostasis

Our study revealed that $A$. tripolium had higher initial content of $\mathrm{Na}^{+}, \mathrm{K}^{+}$and $\mathrm{Cl}^{-}$ions than A. alpinus. In this respect, a classification of the studied species into halophyte and glycophyte was substantiated (Cheeseman 2015). Under salinity, both species accumulated $\mathrm{Na}^{+}$ and $\mathrm{Cl}^{-}$and translocated them to the shoots, but in the halophyte these processes were far more intense than in the glycophyte. Contrary to this study, other halophytes were found to restrict $\mathrm{Na}^{+}$and $\mathrm{Cl}^{-}$uptake in comparison with non-tolerant species (Ellouzi et al. 2014; Prerostova et al. 2017). Our results could be attributed to the species-specific requirement for maintaining high $\mathrm{Na}^{+}$in order to activate water-saving mechanisms (Kerstiens et al. 2002). High capacity to accumulate $\mathrm{Na}^{+}$and $\mathrm{Cl}^{-}$without serious growth inhibition can be a promising feature for future exploitation of A. tripolium in phytodesalination experiments on low and moderately saline soils.

The investigated species had distinct patterns of $\mathrm{K}^{+}$ concentration. In the halophyte, its initial content was over twice as high as in the glycophyte, and it declined under moderate and high salinity. Generally, halophytes are reported to accelerate $\mathrm{K}^{+}$uptake when exposed to saline soil (Gharbi et al. 2017). However, in A. tripolium, the initial $\mathrm{K}^{+}$content seems to be high enough to assure normal functioning, even if $\mathrm{K}^{+}$concentration drops due to excessive $\mathrm{Na}^{+}$uptake and competitiveness for binding sites in ion transporters (Wang et al. 2013). It is also possible that in salt-exposed A. tripolium $\mathrm{Na}^{+}$may be a more crucial ion than $\mathrm{K}^{+}$, as reported for halophyte $S$. portulacastrum (Wang et al. 2012). Since elevated $\mathrm{Na}^{+}$amounts are toxic for both glycophytes and halophytes, the latter species usually have more efficient of $\mathrm{Na}^{+}$detoxification mechanism based on sequestrating the ions in the vacuole (Ali and Yun 2017). However, even under high salinity, where the most pronounced decrease occurred, $\mathrm{K}^{+}$content still exceeded the content in the glycophyte. The response of A. alpinus to salinity was the same as in other non-salt tolerant species. $\mathrm{K}^{+}$content did not change, which contributed to deregulation of ion homeostasis caused by enhanced $\mathrm{Na}^{+}$uptake (Ellouzi et al. 2014).

Osmotic adjustment and osmoprotection

Osmotic adjustment via accumulation of osmolytes is a common response to salinity activated in both tolerant and sensitive species (Gong et al. 2005). We found that in salt-tolerant $A$. tripolium the main changes in the carbohydrate profile involved intense accumulation of uronic acids, mannitol, and, to a lower extent, sucrose. Uronic acids provide efficient water storage and are capable of neutralizing $\mathrm{Na}^{+}$excess (Jaiswar and Kazi 2016). Functions of mannitol in salt-tolerant organisms, particularly alga, involve osmoprotection and radical scavenging (Patel and Williamson 2016). Although its accumulation is rarely observed in halophytes (Slama et al. 2015), we previously reported that in A. tripolium mannitol was specifically accumulated under salt exposure, and was not up-synthesized in response to metallic stress (neither $\mathrm{Cd}$ nor $\mathrm{Pb}$-induced) (Wiszniewska et al. 2019). In this respect, mannitol synthesis under salinity could be regarded as an adaptive mechanism of osmoprotection in the studied halophyte. It can be also assumed that carbohydrate accumulation pattern in saltexposed A. tripolium is oriented towards protection of cell compartments and proteins from dehydration.

Carbohydrate profiling in glycophytic A. alpinus showed that salinity enhanced accumulation of total soluble carbohydrates, mono- and disaccharides, and uronic acids. Glucose accumulation played the major role under salinity, and the accumulation of sucrose was less intense (data not shown). This was inevitably directed towards osmotic adjustment, but also could be linked to energy requirements and regulatory pathways under stress (Dong and Beckles 2019; Hu et al. 2012). In this species, polyol content did not change under 
salinity, suggesting the absence of similar osmoprotection mechanisms as observed in A. tripolium.

Both species experienced depletion of oligosaccharide content under salinity. The main fraction in this group were fructans. Non-stressed A. alpinus was particularly rich in kestose and nystose, the levels of which dropped dramatically under salinity. Storage function of these inuline-type oligosaccharides was replaced by their utilization as carbon source and potential ROS scavengers (Dong and Beckles 2019; Van den Ende 2013).

Osmotic adjustment under salinity involved also amino acid accumulation, mainly by enhanced synthesis of proline and betaines, and such a response was more pronounced in the glycophyte than in the halophyte. This involved particularly ProB synthesis, which was virtually absent in the halophyte unless high salinity was applied. Salinity tolerance in halophytes is usually attributed to their higher content of Pro and betaines, as well as to the ability of their rapid and intensive synthesis (Benjamin et al. 2019; Ellouzi et al. 2014; PardoDomènech et al. 2016). Our study showed that glycophytic $A$. alpinus had also considerable potential to counteract dehydration by intensification of amino acid accumulation. Proline is usually synthesized for rapid utilization, while betaines, particularly ProB, for prolonged storage (Slama et al. 2015). Both routes of amino acid utilization were activated in the glycophyte, while in the halophyte the first one prevailed. Although accumulation of betaines was pronounced in the glycophyte, it did not correspond to higher antioxidant capacity, as reported for other species (Rady et al. 2018; Youssef et al. 2018). Taking into account high initial content of these osmoprotectants in A. alpinus, further studies on the species abiotic stress resistance are substantiated.

\section{Counteracting oxidative stress}

We observed differences in the redox state and functioning of antioxidant system under salinity conditions between the studied species. The halophyte had initially higher content of MDA, what is usually attributed to higher level of oxidative damage (Anjum et al. 2015). However, control MDA concentrations (below $20 \mathrm{nmol} \cdot \mathrm{g}^{-1} \mathrm{DW}$ ) were still considerably low, suggesting occurrence of typical cellular metabolism, as in salttolerant Cakile maritima and Thellungiella salsuginea
(Ellouzi et al. 2014). Hence, in A. tripolium oxidative stress was inefficiently counterbalanced only at high salinity conditions. This is corroborated by the fact that the halophyte had very high initial activity of CAT and POD, in comparison with the glycophyte, which did not change under low salinity and only partially (POD) at moderate salinity. Under high salinity, POD activity declined substantially, and simultaneously MDA content rapidly increased. Also the contents of nonenzymatic antioxidants, both total phenolics and carotenoids, were considerably higher in the halophyte than in the glycophyte subjected to respective salinity conditions. Although in both species TPC and Car concentrations progressively declined with increasing salinity, their levels were higher in the halophyte than in the glycophyte. It seems that boosted activity of antioxidant enzymes and enhanced accumulation of non-enzymatic antioxidants were involved in constitutive protective mechanisms under low and moderate salinity in A. tripolium. This is in agreement with previous studies reporting that metabolites responsible for stress defense mechanisms are usually more abundant in pre-stress conditions in salt-resistant than in salt-sensitive species (Gharbi et al. 2017; Gong et al. 2005; Prerostova et al. 2017). An interesting exception from this pattern observed in our study was accumulation of flavonoids. Their initial content was higher in the glycophytic A. alpinus in comparison with A. tripolium. Although in both species enhanced synthesis of FV occurred as a response to salinity treatments, their content in the glycophyte always exceeded that in the halophyte. There are evidences that this particular group of antioxidant polyphenolics plays a role in metabolic adjustment to both excessive salinity in non-tolerant genotypes (Ismail et al. 2016) and sub-optimal conditions of hyposalinity in obligatory halophytes (Gavin and Durako 2012). FV can be therefore regarded as the first-line defense component of antioxidant system synthesized under stress.

Major PGRs correlating with the functioning of defense mechanisms are distinct in halophyte and glycophyte

Biometrical and biochemical parameters determined in this study were classified into four groups, relevant to general responses to salinity: growth performance, osmotic adjustment, ion accumulation and antioxidant activity. Changes in these parameters occurring at increased salinity levels were analyzed in terms of their 
correlations with the changes in concentrations of endogenous PGRs. This approach revealed main differences in the regulation of defense mechanisms by phytohormones in the studied halophyte and glycophyte.

The glycophyte reactions correlated mostly with the changes in SA and ACC levels, as well as ABA (Fig. 2). These three PGRs are usually listed as main regulators of salinity responses in plants, increasing their osmoregulatory and antioxidant capacity (Cui et al. 2015; Van de Poel and Van Der Straeten 2014; Stetsenko et al. 2015), thus the glycophyte reaction was rather typical in this respect. It is worth mentioning that the contents of SA and ACC were interdependent, and some parameters, especially concerning growth and antioxidant activity, also correlated with both of these regulators. Contrary to that, no correlations were found for the pool of auxins, and very limited for Cyt and GA, suggesting that growth promoters were irrelevant for the glycophyte responses to salt exposure. This was rather unexpected, as accumulation of these PGRs substantially increased in A. alpinus under stress. Certainly, a tolerance mechanism based on growth retardation in order to minimize loss and survive harsh saline conditions was not activated in this species (Grigore et al. 2012). Unlike in the glycophyte, in the salt-treated halophyte an important role of growth promoters, Cyt, Aux and GA, was observed, although their contents were lower than in the glycophyte. At the same time, none of the growth inhibitors, such as ABA or ethylene precursor, were found to correlate with the determined parameters. Instead, vast responses of the salt-tolerant species were controlled by changes in the concentrations of benzoic acid and jasmonates and also by an interesting interplay between the pools of gibberellins and jasmonates (Fig. 2). The relationship between JA and GA pools is usually antagonistic in stressed plants (Heinrich et al. 2013; Wasternack and Hause 2013). It was particularly visible among the parameters depicting osmotic adjustment: accumulation of ions and organic osmolytes in $A$. tripolium. Progressive accumulation of osmolytes $\mathrm{Na}^{+}, \mathrm{Cl}^{-}$, Pro, GlyB, polyols and mono- and disaccharides) under salinity positively correlated with GA, and negatively with JA contents. Reverse correlations occurred for the concentrations of $\mathrm{K}^{+}$and oligosaccharides, the contents of which decreased under salt treatment. None of the determined parameters correlated with JA pool in our glycophyte. It can be related to ineffective osmotic adjustment in this species, based mainly on glucose and ProB accumulation. A recent study showed that jasmonate signaling may be crucial for GlyB accumulation (Xu et al. 2018), whereas our results suggest that there is no such correlation when ProB synthesis is considered in salt-sensitive Aster species.

Enhanced accumulation of SA has been related to mitigation of salt stress effects in plants (Farhangi-Abriz and Ghassemi-Golezani 2018; Gharbi et al. 2017; Youssef et al. 2018). This compound is involved in the regulation of water loss and osmotic conditions during salt exposure, as confirmed in our study in the glycophyte A. alpinus. However, we observed that in the halophytic A. tripolium benzoic acid, an intermediate compound in PAL-dependent synthesis pathway (Miura and Tada 2014), rather than SA itself, seemed to play a role in modulating defense reactions under salinity. Indeed, our previous study showed that SA was not involved in salinity response in A. tripolium (Wiszniewska et al. 2019). Similar reaction was also reported in a halophyte $P$. strombulifera (Devinar et al. 2013). According to Senaratna et al. (2003), it can be assumed that in A. tripolium BA is utilized as a signal molecule that controls activation of defense mechanisms under stress. It can be linked to alteration in SA biosynthesis pathway that results in low SA accumulation and BA amassment (Sawada et al. 2006). Our results support the recent opinion that the blockage of SA synthesis is associated with enhanced salinity tolerance (Llanes et al. 2018). The fact that numerous parameters depicting tolerance mechanisms in the halophyte correlated with the content of BA rather than SA is novel, and these relationships should be further investigated.

\section{Conclusions}

Our comparative analysis of the functioning of salinity defense mechanisms in related halophyte and glycophyte Aster species revealed that both species activated typical salt stress-protecting mechanisms: osmotic adjustment by ion uptake regulation and synthesis of compatible solutes, as well as counteracting oxidative damage. Effective interplay of these mechanisms enabled plant growth under progressive salinity. In the halophytic A. tripolium, metabolic modifications became apparent at moderate and high salt concentrations, suggesting that low salinity was not perceived as a stress factor. On the other hand, in the glycophytic A. alpinus defense reactions were activated at all salinity levels. As 
revealed by the metabolite profiling, the detailed pattern of observed responses was species-specific, and was manifested by synthesis, accumulation or activity of distinct compounds in order to achieve the protective effect. This was particularly visible in the case of osmoprotectant synthesis. Our study linked these differences to altered phytohormonal regulation in salttolerant and salt-sensitive plants. The responses of the glycophyte were mostly controlled by changes in the level of endogenous stress hormones: ABA and ethylene precursor ACC, aided also by SA. The halophyte reactions involved changes in the content of plant growth promoters (particularly Aux, but also Cyt and GA), JA and BA. Our study demonstrated that salt tolerance in the studied Aster plants is conveyed by benzoic acid rather than salicylic acid and that elevated SA content may even suppress stress tolerance. An important element of salt tolerance trait is also JA-GA network that influences the intensity of particular defense responses. The metabolite profiling also identified features possibly accounting for the glycophyte A. alpinus potential to survive abiotic stress conditions. The study reveals new aspects of internal phytohormonal regulation of plant response to salt excess and enables further insight into extremophyte biology.

Supplementary Information The online version contains supplementary material available at https://doi.org/10.1007/s11104021-04889-x.

Acknowledgements Not applicable.

Author contribution Conceptualization: Alina Wiszniewska, Ewa Hanus-Fajerska.

Methodology: Aleksandra Koźmińska. Kinga Dziurka, Michał Dziurka.

Formal analysis and investigation: Alina Wiszniewska, Aleksandra Koźmińska.

Writing - original draft preparation: Alina Wiszniewska, Aleksandra Koźmińska.

Writing - review and editing: Alina Wiszniewska, Kinga Dziurka, Michał Dziurka.

Funding acquisition: Ewa Hanus-Fajerska.

Resources: Alina Wiszniewska, Aleksandra Koźmińska.

Supervision: Ewa Hanus-Fajerska.

Funding This study was financed by Ministry of Science and Higher Education of the Republic of Poland (050012-D011/D017) - statutory funding of research activity held at University of Agriculture in Kraków, Poland.

\section{Declarations}

Conflict of interests Authors declare no conflict of interests.

Open Access This article is licensed under a Creative Commons Attribution 4.0 International License, which permits use, sharing, adaptation, distribution and reproduction in any medium or format, as long as you give appropriate credit to the original author(s) and the source, provide a link to the Creative Commons licence, and indicate if changes were made. The images or other third party material in this article are included in the article's Creative Commons licence, unless indicated otherwise in a credit line to the material. If material is not included in the article's Creative Commons licence and your intended use is not permitted by statutory regulation or exceeds the permitted use, you will need to obtain permission directly from the copyright holder. To view a copy of this licence, visit http://creativecommons.org/licenses/by/4.0/.

\section{References}

Aebi H (1984) Catalase in vitro. In: Packer L (ed) Oxygen radicals in biological systems. Methods in enzymology, vol 105. Elsevier Academic Press, pp 121-126

Al Hassan M, Chaura J, Donat-Torres MP, Boscaiu M, Vicente O (2017) Antioxidant responses under salinity and drought in three closely related wild monocots with different ecological optima. AoB Plants 9(2). https://doi.org/10.1093 /aobpla/plx009

Ali A, Yun D-J (2017) Salt stress tolerance; what do we learn from halophytes? J Plant Biol 60(5):431-439

Anjum NA, Sofo A, Scopa A, Roychoudhury A, Gill SS, Iqbal M, Lukatkin AS, Pereira E, Duarte AC, Ahmad I (2015) Lipids and proteins - major targets of oxidative modifications in abiotic stressed plants. Environ Sci Pollut Res 22(6):40994121

Bartels D, Dinakar C (2013) Balancing salinity stress responses in halophytes and non-halophytes: a comparison between Thellungiella and Arabidopsis thaliana. Funct Plant Biol 40(9):819-831

Benjamin JJ, Lucini L, Jothiramshekar S, Parida A (2019) Metabolomic insights into the mechanisms underlying tolerance to salinity in different halophytes. Plant Physiol Biochem 135:528-545

Bercu R, Făgăraș M, Broasca L (2012) Anatomical features of Aster tripolium L. (Asteraceae) to saline environments. Ann RSCB 17(1):271-277

Cheeseman JM (2015) The evolution of halophytes, glycophytes and crops, and its implications for food security under saline conditions. New Phytol 206(2):557-570

Cui M, Lin Y, Zu Y, Efferth T, Li D, Tang Z (2015) Ethylene increases accumulation of compatible solutes and decreases oxidative stress to improve plant tolerance to water stress in Arabidopsis. J Plant Biol 58(3):193-201

Devinar G, Llanes A, Masciarelli O, Luna V (2013) Different relative humidity conditions combined with chloride and 
sulfate salinity treatments modify abscisic acid and salicylic acid levels in the halophyte Prosopis strombulifera. Plant Growth Regul 70(3):247-256

Dias DA, Hill CB, Jayasinghe NS, Atieno J, Sutton T, Roessner U (2015) Quantitative profiling of polar primary metabolites of two chickpea cultivars with contrasting responses to salinity. J Chromatogr B Anal Technol Biomed Life Sci 1000:1-13

Dong S, Beckles DM (2019) Dynamic changes in the starch-sugar interconversion within plant source and sink tissues promote a better abiotic stress response. J Plant Physiol 234-235:8093

Duarte B, Goessling JW, Marques JC, Caçador I (2015) Ecophysiological constraints of Aster tripolium under extreme thermal events impacts: merging biophysical, biochemical and genetic insights. Plant Physiol Biochem 97: 217-228

Dubois M, Gilles KA, Hamilton JK, Rebers PA, Smith F (1995) Colorimetric method for determination of sugars and related substances. Anal Chem. ACS Publications. Available from: https://doi.org/10.1021/ac60111a017, Colorimetric Method for Determination of Sugars and Related Substances

Ellouzi H, Ben HK, Hernández I, Cela J, Müller M, Magné C et al (2014) A comparative study of the early osmotic, ionic, redox and hormonal signaling response in leaves and roots of two halophytes and a glycophyte to salinity. Planta 240(6):12991317

Eyidogan F, Oz MT, Yucel M, Oktem HA (2012) Signal transduction of phytohormones under abiotic stresses. In: Phytohormones and abiotic stress tolerance in plants. Springer-Verlag, Berlin Heidelberg, pp 1-48

Farhangi-Abriz S, Ghassemi-Golezani K (2018) How can salicylic acid and jasmonic acid mitigate salt toxicity in soybean plants? Ecotoxicol Environ Saf 147:1010-1016

Filippova GV, Androsova DN, Filippov EV, Prokopev IA (2019) Influence of temperature and precipitation on the morphology, growth, and stress resistance of seeds of some representatives of northern flora. Russ J Ecol 50:517-525. https://doi. org/10.1134/S1067413619050047

Flowers TJ, Colmer TD (2015) Plant salt tolerance: adaptations in halophytes. Ann Bot 115(3):327-331

Flowers TJ, Galal HK, Bromham L (2010) Evolution of halophytes: multiple origins of salt tolerance in land plants. CSIRO [Internet]. [cited 2020 Apr 21];37(7):604-12. Available from: www.publish.csiro.au/journals/fpb

Gavin NM, Durako MJ (2012) Localization and antioxidant capacity of flavonoids in Halophila johnsonii in response to experimental light and salinity variation. J Exp Mar Bio Ecol 416-417:32-40

Gharbi E, Martínez JP, Benahmed H, Hichri I, Dobrev PI, Motyka $\mathrm{V}$ et al (2017) Phytohormone profiling in relation to osmotic adjustment in NaCl-treated plants of the halophyte tomato wild relative species Solanum chilense comparatively to the cultivated glycophyte Solanum lycopersicum. Plant Sci 1;258:77-89

Gong Q, Li P, Ma S, Indu Rupassara S, Bohnert HJ (2005) Salinity stress adaptation competence in the extremophile
Thellungiella halophila in comparison with its relative Arabidopsis thaliana. Plant J 44(5):826-839

Grigore MN, Villanueva M, Boscaiu M, Vicente O (2012) Do halophytes really require salts for their growth and development? An experimental approach. Not Sci Biol 4(2):23-29

Guo J, Lu C, Zhao F, Gao S, Wang B (2020) Improved reproductive growth of euhalophyte Suaeda salsa under salinity is correlated with altered phytohormone biosynthesis and signal transduction. Funct Plant Biol 47(2):170

Heinrich M, Hettenhausen C, Lange T, Wünsche H, Fang J, Baldwin IT, Wu J (2013) High levels of jasmonic acid antagonize the biosynthesis of gibberellins and inhibit the growth of Nicotiana attenuata stems. Plant J 73(4):591-606

Hodges DM, DeLong JM, Forney CF, Prange RK (1999) Improving the thiobarbituric acid-reactive-substances assay for estimating lipid peroxidation in plant tissues containing anthocyanin and other interfering compounds. Planta 207(4): 604-611

Hu M, Shi Z, Zhang Z, Zhang Y, Li H (2012) Effects of exogenous glucose on seed germination and antioxidant capacity in wheat seedlings under salt stress. Plant Growth Regul 68(2):177-188

Ismail H, Dragišic Maksimovic J, Maksimovic V, Shabala L, Živanovic BD, Tian Y, Jacobsen SE, Shabala S (2016) Rutin, a flavonoid with antioxidant activity, improves plant salinity tolerance by regulating $\mathrm{K}^{+}$retention and $\mathrm{Na}^{+}$exclusion from leaf mesophyll in quinoa and broad beans. Funct Plant Biol 43(1):75

Jaiswar S, Kazi MA (2016) Composition and localization of mucilage under short term $\mathrm{NaCl}$ stress in Salicornia brachiata roxb. And Suaeda maritima (L.) dumort. Indian J Nat Prod Resour 7(2):162-168

Joshi R, Mangu VR, Bedre R, Sanchez L, Pilcher W, Zandkarimi H, Baisakh N (2015) Salt adaptation mechanisms of Halophytes: improvement of salt tolerance in crop plants. In: Pandey G (ed) Elucidation of abiotic stress signaling in plants. Springer, New York. https://doi.org/10.1007/978-14939-2540-7_9

Julkowska MM, Testerink C (2015) Tuning plant signaling and growth to survive salt. Trends Plant Sci 20(9):586-594

Kerstiens G, Tych W, Robinson MF, Mansfield TA (2002) Sodium-related partial stomatal closure and salt tolerance of Aster tripolium. New Phytol 153:509-515

Koźmińska A, Al Hassan M, Wiszniewska A, Hanus-Fajerska E, Boscaiu M, Vicente O (2019) Responses of succulents to drought: comparative analysis of four Sedum (Crassulaceae) species. Sci Hortic 243:235-242

Korolyuk EA (1997) Aster L. In: Krasnoborov IM (ed) Flora Sibiri, vol. 13. Asteraceae (Compositae) [Flora of Siberia, vol. 13. Asteraceae (Compositae)]. Nauka Publ., Novosibirsk, pp 32-34

Kumari A, Parida AK (2018) Metabolomics and network analysis reveal the potential metabolites and biological pathways involved in salinity tolerance of the halophyte Salvadora persica. Environ Exp Bot 148:85-99 
Kumari A, Das P, Parida AK, Agarwal PK (2015) Proteomics, metabolomics, and ionomics perspectives of salinity tolerance in halophytes. Front Plant Sci 29;6(JULY):537

Li B, Li N, Duan X, Wei A, Yang A, Zhang J (2010) Generation of marker-free transgenic maize with improved salt tolerance using the FLP/FRT recombination system. J Biotechnol 145(2):206-213

Lichtenthaler HK, Buschmann C (2001) Chlorophylls and carotenoids: measurement and characterization by UV-VIS spectroscopy. Curr Protoc Food Anal Chem 1(1):F4.3.1-F4.3.8

Llanes A, Reginato M, Devinar G, Luna V (2018) What is known about phytohormones in halophytes? A review. Biologia 73: $727-742$

Lück H (1962) Peroxidase. In: Bergmeyer HU (ed) Methoden der enzymatischen analyse. Verlag Chemie, Weinheim, pp 895897

Maršálová L, Vítámvás P, Hynek R, Prášil IT, Kosová K (2016) Proteomic response of Hordeum vulgare cv. Tadmor and Hordeum marinum to salinity stress: similarities and differences between a glycophyte and a halophyte. Front Plant Sci 7(AUG2016): 1154

Miura K, Tada Y (2014) Regulation of water, salinity, and cold stress responses by salicylic acid. Front Plant Sci 5:4

Pardo-Domènech LL, Tifrea A, Grigore MN, Boscaiu M, Vicente O (2016) Proline and glycine betaine accumulation in two succulent halophytes under natural and experimental conditions. Plant Biosyst 150(5):904-915

Patel TK, Williamson JD (2016) Mannitol in plants, fungi, and plant-fungal interactions. Trends Plant Sci 21(6):486-497

Peleg Z, Blumwald E (2011) Hormone balance and abiotic stress tolerance in crop plants. Curr Opin Plant Biol 14(3):290-295

Pennisi E (2001) Taxonomy. Linnaeus's Last Stand? Science (80) 291(5512):2304-2307

Pieterse CMJ, Leon-Reyes A, Van Der Ent S, Van Wees SCM (2009) Networking by small-molecule hormones in plant immunity. Vol. 5, nature chemical biology. Nat Publ Group 2009:308-316

Prerostova S, Dobrev PI, Gaudinova A, Hosek P, Soudek P, Knirsch V, Vankova R (2017) Hormonal dynamics during salt stress responses of salt-sensitive Arabidopsis thaliana and salt-tolerant Thellungiella salsuginea. Plant Sci 264: 188-198

Rady MOA, Semida WM, Abd El-Mageed TA, Hemida KA, Rady MM (2018) Up-regulation of antioxidative defense systems by glycine betaine foliar application in onion plants confer tolerance to salinity stress. Sci Hortic 240:614-622

Rozema J, Schat H (2013) Salt tolerance of halophytes, research questions reviewed in the perspective of saline agriculture. Environ Exp Bot 92:83-95

Sawada H, Shim IS, Usui K (2006) Induction of benzoic acid 2hydroxylase and salicylic acid biosynthesis-modulation by salt stress in rice seedlings. Plant Sci 171(2):263-270

Senaratna T, Merritt D, Dixon K, Bunn E, Touchell D, Sivasithamparam K (2003) Benzoic acid may act as the functional group in salicylic acid and derivatives in the induction of multiple stress tolerance in plants. Plant Growth Regul 39(1):77-81
Shabala S (2013) Learning from halophytes: physiological basis and strategies to improve abiotic stress tolerance in crops. Ann Bot 112(7):1209-1221

Sharma A, Shahzad B, Kumar V, Kohli SK, Sidhu GPS, Bali AS, Handa N, Kapoor D, Bhardwaj R, Zheng B (2019) Phytohormones regulate accumulation of osmolytes under abiotic stress. Biomolecules 9(7):285

Shennan C, Hunt R, Macrobbie EAC (1987) Salt tolerance in Aster tripolium L. I The effect of salinity on growth Plant Cell Environ 10(1):59-65. https://doi.org/10.1111/j.13653040.1987.tb02080.x

Singleton VL, Orthofer R, Lamuela-Raventós RM (1999) Analysis of total phenols and other oxidation substrates and antioxidants by means of folin-ciocalteu reagent. Methods Enzymol 299:152-178

Slama I, Abdelly C, Bouchereau A, Flowers T, Savouré A (2015) Diversity, distribution and roles of osmoprotective compounds accumulated in halophytes under abiotic stress. Ann Bot 115(3):433-447

Soundararajan P, Manivannan A, Jeong BR (2019) Different antioxidant defense systems in halophytes and glycophytes to overcome salinity stress. Springer, Champ, pp 335-347

Souza LA, Monteiro CC, Carvalho RF, Gratão PL, Azevedo RA (2017) Dealing with abiotic stresses: an integrative view of how phytohormones control abiotic stress-induced oxidative stress. Theor Exp Plant Physiol 29(3):109-127

Stetsenko LA, Vedenicheva NP, Likhnevsky RV, Kuznetsov VV (2015) Influence of abscisic acid and fluridone on the content of phytohormones and polyamines and the level of oxidative stress in plants of Mesembryanthemum crystallinum L. under salinity. Biol Bull 42(2):98-107

Szeląg Z, Kobiv Y (2017) Typification of Aster alpinus var. glabratis (Asteraceae). Polish Botanical Journal 62(2):301303

Van de Poel B, Van Der Straeten D (2014) 1-aminocyclopropane1-carboxylic acid (ACC) in plants: More than just the precursor of ethylene! Vol. 5, Frontiers in Plant Science. Frontiers Media S.A. p. 1-11

Van den Ende W (2013) Multifunctional fructans and raffinose family oligosaccharides. Front Plant Sci 4:1-11

Ventura Y, Myrzabayeva M, Alikulov Z, Cohen S, Shemer Z, Sagi M (2013) The importance of iron supply during repetitive harvesting of Aster tripolium. Funct Plant Biol 40(9):968976

Wang D, Wang H, Han B, Wang B, Guo A, Zheng D, Liu C, Chang L, Peng M, Wang X (2012) Sodium instead of potassium and chloride is an important macronutrient to improve leaf succulence and shoot development for halophyte Sesuvium portulacastrum. Plant Physiol Biochem 51:53-62

Wang M, Zheng Q, Shen Q, Guo S (2013) The critical role of potassium in plant stress response. Int J Mol Sci 14(4):73707390

Wasternack C, Hause B (2013) Jasmonates: biosynthesis, perception, signal transduction and action in plant stress response, growth and development. An update to the 2007 review in annals of botany. Ann Bot 111(6):1021-1058 
Wiszniewska A, Koźmińska A, Hanus-Fajerska E, Dziurka M, Dziurka K (2019) Insight into mechanisms of multiple stresses tolerance in a halophyte Aster tripolium subjected to salinity and heavy metal stress. Ecotoxicol Environ Saf 180:12-22

Xu Z, Sun M, Jiang X, Sun H, Dang X, Cong H et al (2018) Glycinebetaine biosynthesis in response to osmotic stress depends on jasmonate signaling in watermelon suspension cells. Front Plant Sci Oct 12:9

Youssef SM, Abd Elhady SA, Aref RM, Riad GS (2018) Salicylic acid attenuates the adverse effects of salinity on growth and yield and enhances peroxidase isozymes expression more competently than proline and glycine betaine in cucumber plants. Gesunde Pflanz 70(2):75-90

Zhishen J, Mengcheng T, Jianming W (1999) The determination of flavonoid contents in mulberry and their scavenging effects on superoxide radicals. Food Chem 64(4):555-559

Publisher's note Springer Nature remains neutral with regard to jurisdictional claims in published maps and institutional affiliations. 